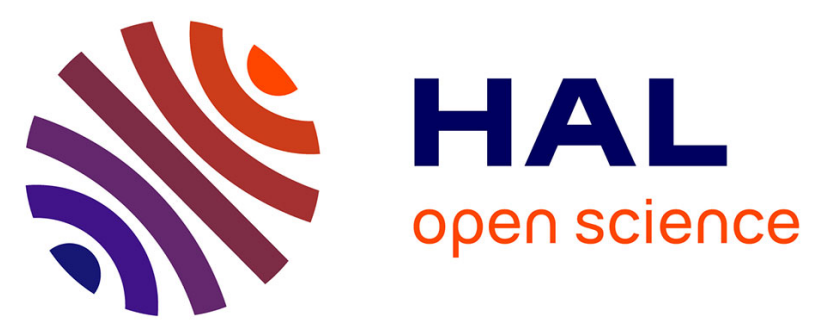

\title{
Spectroscopic Signature and Structure of Active Centers in Ziegler-Natta Polymerization Catalysts revealed by Electron Paramagnetic Resonance
}

Anton Ashuiev, Matthieu Humbert, David Gajan, Sebastien Norsic, Jan

Blahut, Keith Searles, Daniel Klose, Anne Lesage, Guido Pintacuda, Jean

Raynaud, et al.

\section{To cite this version:}

Anton Ashuiev, Matthieu Humbert, David Gajan, Sebastien Norsic, Jan Blahut, et al.. Spectroscopic Signature and Structure of Active Centers in Ziegler-Natta Polymerization Catalysts revealed by Electron Paramagnetic Resonance. 2020. hal-03017383

\section{HAL Id: hal-03017383 \\ https://hal.science/hal-03017383}

Preprint submitted on 20 Nov 2020

HAL is a multi-disciplinary open access archive for the deposit and dissemination of scientific research documents, whether they are published or not. The documents may come from teaching and research institutions in France or abroad, or from public or private research centers.
L'archive ouverte pluridisciplinaire HAL, est destinée au dépôt et à la diffusion de documents scientifiques de niveau recherche, publiés ou non, émanant des établissements d'enseignement et de recherche français ou étrangers, des laboratoires publics ou privés. 


\section{Spectroscopic Signature and Structure of Active Centers in Ziegler-Natta Polymerization Catalysts revealed by Electron Paramagnetic Resonance}

Anton Ashuiev, mathieu humber, david gajan, sebastien norsic, jean blahut, Keith Searles, Daniel Klose, Anne Lesagee, Guido Pintacuda, Jean Raynaud, Vincent Monteil, Christophe coperet, Gunnar Jeschke

Submitted date: $24 / 08 / 2020$ - Posted date: 25/08/2020

Licence: CC BY-NC-ND 4.0

Citation information: Ashuiev, Anton; humber, mathieu; gajan, david; norsic, sebastien; blahut, jean; Searles, Keith; et al. (2020): Spectroscopic Signature and Structure of Active Centers in Ziegler-Natta Polymerization Catalysts revealed by Electron Paramagnetic Resonance. ChemRxiv. Preprint. https://doi.org/10.26434/chemrxiv.12854777.v2

Despite decades of extensive studies, the atomic-scale structure of active sites in heterogeneous Ziegler-Natta (ZN) catalysts remains elusive and a matter of debate. Here, the structure of polymerization ZN catalysts is elucidated from magnetic resonance experiments carried out on samples reacted with increasing amounts of $\mathrm{BCl}_{3}$ so as to enhance the concentration of active sites and observe clear spectroscopic signatures. Notably, we show that EPR and NMR spectroscopy of the activated ZN catalysts enables to observe paramagnetic species whose amount increases in conjunction with the catalytic activity. The joint application of 2D HYSCORE experiments and DFT calculations reveals the presence of bimetallic alkyl-Ti(III),Al complexes that are assigned to the catalytic centers of $\mathrm{MgCl}_{2}$-supported Ziegler-Natta catalysts

File list (2)

Main_final_ChemRXIV.pdf (2.10 MiB)

view on ChemRxiv • download file

SI_final_ChemRXIV.pdf (6.67 MiB)

view on ChemRxiv - download file 


\title{
Spectroscopic Signature and Structure of Active Centers in Ziegler-Natta Polymerization Catalysts revealed by Electron Paramagnetic Resonance
}

\author{
A. Ashuiev ${ }^{1 \neq}$, M. Humbert ${ }^{2 \ddagger}$, S. Norsic ${ }^{2}$, J. Blahut ${ }^{3}$, D. Gajan ${ }^{3}$, K. Searles ${ }^{1}$, D. Klose ${ }^{1}$, A. Lesage ${ }^{3}$, \\ G. Pintacuda ${ }^{3}$, J. Raynaud $^{2 *}$, V. Monteil ${ }^{2 *}$, C. Copéret ${ }^{1 *}$, G. Jeschke ${ }^{1^{*}}$ \\ ${ }^{1}$ Department of Chemistry and Applied Biosciences, ETH Zurich, Wolfgang-Pauli-Strasse 1-5, \\ 8093 Zurich, Switzerland. \\ ${ }^{2}$ Université de Lyon, Univ. Lyon 1, CPE Lyon, CNRS, Chimie Catalyse Polymères et Procédés \\ (C2P2), LCPP team, 43 Bd du 11 novembre 1918, 69616 Villeurbanne, France. \\ ${ }^{3}$ Univ Lyon, ENS Lyon, Université Lyon 1, CNRS, High-Field NMR Center of Lyon, FRE 2034, \\ F-69100 VILLEURBANNE, France. \\ *Email: jean.raynaud@univ-lyon1.fr (J. R.); vincent.monteil@univ-lyon1.fr (V. M.); \\ ccoperet@inorg.chem.ethz.ch (C. C.); gunnar.jeschke@phys.chem.ethz.ch (G. J.)
}

${ }^{\ddagger}$ A. Ashuiev and M. Humbert declare equal contribution.

Despite decades of extensive studies, the atomic-scale structure of active sites in heterogeneous Ziegler-Natta $(\mathrm{ZN})$ catalysts remains elusive and a matter of debate. Here, the structure of polymerization $\mathrm{ZN}$ catalysts is elucidated from magnetic resonance experiments carried out on samples reacted with increasing amounts of $\mathrm{BCl}_{3}$ so as to enhance the concentration of active sites and observe clear spectroscopic signatures. Notably, we show that EPR and NMR spectroscopy of the activated $\mathrm{ZN}$ catalysts enables to observe paramagnetic species whose amount increases in conjunction with the catalytic activity. The joint application of 2D HYSCORE experiments and DFT calculations reveals the presence of bimetallic alkyl-Ti(III),Al complexes that are assigned to the catalytic centers of $\mathrm{MgCl}_{2}$-supported Ziegler-Natta catalysts.

$E P R$ spectroscopy and activation with $\mathrm{BCl}_{3}$ enable unraveling the active-center structure of Ziegler-Natta catalysts.

Nowadays, polymers and particularly plastics are the most common products of chemical industry, comprising nearly $80 \%$ of the worldwide industry output (1). Two important polymers, which are widely used for e.g. packaging and construction materials in modern times, are polyethylene and polypropylene; they together sum up to more than half of the total plastics production (2). Such mass production of polyethylene and polypropylene became possible only after discovery of transition metal-based catalysts in the second half of the $20^{\text {th }}$ century, such as Ziegler-Natta catalysts $(3,4)$. With their ability to promote the synthesis of high-density linear polyethylene and stereoregular polypropylene under relatively mild conditions, the Ziegler-Natta catalysts are responsible nowadays for nearly $50 \%$ of worldwide production of polyethylene and around $95 \%$ of overall polypropylene production (5). The boom of their commercial usage arose with the development of heterogeneous $\mathrm{MgCl}_{2}$-supported Ziegler-Natta catalysts $\left(\mathrm{TiCl}_{4} / \mathrm{MgCl}_{2}\right.$ activated with $\mathrm{Et}_{3} \mathrm{Al}$ ) in the 1960 s, which appeared to be nearly 100 times more active than the ones originally proposed by Ziegler and $\operatorname{Natta}(5,6)$. Due to the enormous productivity of such catalysts 
and their unprecedented ability to tune the properties of produced plastics in a controlled way, the supported Ziegler-Natta catalysts became a workhorse of modern polyolefin industry ( 6 ).

Knowledge of the structure of the corresponding active center(s) represents a crucial step for enabling further improvement of the Ziegler-Natta catalytic process. However, despite decades of extensive studies, the atomic-scale description of the catalyst active centers/sites (without or with coordinated monomer) remained so far elusive. Ziegler-Natta catalysts are typically prepared by impregnating a $\mathrm{MgCl}_{2}$ support with $\mathrm{TiCl}_{4}$ that needs to be first treated either mechanically (grinding/ball milling) or chemically with Lewis bases of different types, often oxygen-based such as diethers, alcohols, or THF $(6,7)$. The catalytic Ziegler-Natta polymerization then requires the activation of the obtained precatalyst with an alkylaluminium reagent acting as a co-catalyst, e.g. $\mathrm{Et}_{3} \mathrm{Al}$. According to the proposition of Cossee and Arlman (8), the active site shall include a metalcarbon bond in order to perform ethylene insertion, which points towards Ti alkyl species as the active centers; alkylation of $\mathrm{TiCl}_{4}$ most likely occurs upon addition of aluminum alkyls (Fig. 1).

Based on the activity of homogeneous and supported group IV transition-metal metallocenes towards ethylene polymerization ( 9 - 12), for which cationic M(IV) alkyl species were found to be the active sites (13), Ti(IV) cationic alkyls (A, Fig. 1a) have been proposed as possible active centers of $\mathrm{MgCl}_{2}$-supported Ziegler-Natta catalysts (14). On the other hand, the addition of aluminum alkyls leads to a reduction of a large amount of Ti(IV) (15). Based on the estimated correlation of polymerization activity with the general amount of $\mathrm{Ti}^{3+}$ species (16), $\mathrm{Ti}(\mathrm{III})$ alkyls (B, Fig. 1a) have been proposed to be the active species (17). This proposition is further supported by a recent finding that well-defined Ti(III) neutral alkyls are efficient ethylene polymerization catalysts, where the presence of an unpaired electron favors $\mathrm{C}_{2} \mathrm{H}_{4}$ polymerization (18), and by the activity of silica-supported Ti(III) hydrides towards ethylene polymerization (19, 20). In fact, Giulio Natta himself proposed that the Ziegler-Natta catalysts could be bimetallic Ti(III) - Al complexes containing organometallic bonds $(21)$ that could be interpreted as Ti(III)- $\left(\mu_{2}-\mathrm{Cl}\right)-\left(\mu_{2}-\right.$ $\mathrm{R})-\mathrm{AlR}_{2}$ type $(\mathbf{C}$, Fig. 1a). This structure is also the cornerstone of the Rodriguez-Van Looy mechanism (22), which extends upon Cossee \& Arlman's and proposes a bimetallic species to explain the stereospecificity of ZN-catalyzed propylene polymerization (22). So far, however, there has been no direct evidence for any of these proposed structures.

The difficulty of spectroscopic characterization of the active species of heterogeneous ZieglerNatta catalysts is mostly related to the small amounts of those sites compared to the overall $\mathrm{Ti}$ amount. This problem may be addressed by investigating catalysts treated with strong Lewis acids, e.g. $\mathrm{BCl}_{3}$ (Fig. 1b), which has been shown to significantly enhance the catalytic activity and therefore the number of active sites $(23,24)$, thereby opening new opportunities to capture spectroscopic signatures. Here, we report the structural characterization by EPR and NMR spectroscopies of these highly active Ziegler-Natta catalysts for ethylene polymerization treated with different amounts of $\mathrm{BCl}_{3}$. Figure 1a shows schematically the protocol used to prepare the ZN samples used in this study.

\section{Spectroscopic identification of the active species of Ziegler-Natta heterogeneous catalysts}

As previously observed (24), the addition of $\mathrm{BCl}_{3}$ continuously increases the activity of the Ziegler-Natta catalyst from $9 \mathrm{~kg}_{\mathrm{PE}} \cdot\left(\mathrm{g}_{\mathrm{cat}} \mathrm{h}\right)^{-1}$ up to the maximal value of $38 \mathrm{~kg}_{\mathrm{PE}} \cdot\left(\mathrm{g}_{\text {cat }} \mathrm{h}\right)^{-1}$ (Fig. $2 \mathrm{a}$ and Table S1). At the same time, the average molar masses $M_{\mathrm{n}}$ and $M_{\mathrm{w}}$ as well as the corresponding dispersity $Ð$ of produced polyethylene remain essentially the same upon $\mathrm{BCl}_{3}$ addition. This is strong evidence that the structure of the active centers of the Ziegler-Natta catalysts is not changed 
and that the active-site concentration increases with addition of $\mathrm{BCl}_{3}$, as discussed in a previous investigation based on a combination of kinetics and polymerization results (24). The activation by $\mathrm{Et}_{3} \mathrm{Al}$ of samples prepared with different $\mathrm{BCl}_{3}$ loading (Fig. 1b) was studied by NMR and pulse EPR spectroscopies (see SM Materials and Methods). A low [Al]/[Ti] ratio ( 10), ca. one order of magnitude lower than typical ratios employed in ZN-catalyzed polymerizations $-100<[\mathrm{Al}] /[\mathrm{Ti}]$ $<400$ (24), - was used for these experiments for practicality. Higher ratios are used for conventional polymerization runs to scavenge impurities from the reaction medium (present in monomer, solvents...) and to maintain high activities throughout the polymerization processes. To ensure that the observed spectroscopic signatures actually relate to active centers, which become active sites in the presence of ethylene, we verified that all alkylated materials prepared under the conditions for the NMR and EPR experiments also displayed the expected polymerization performances (see SM Validation of Spectroscopic Methodology for details, and Table S2).

We first investigated the samples via solid-state NMR. While the ${ }^{11} \mathrm{~B}$ solid-state NMR spectrum of precatalysts (before $\mathrm{Et}_{3} \mathrm{Al}$ addition) shows that all B-containing species are boron alkoxides, resulting from the reaction of $\mathrm{BCl}_{3}$ with either THF or chlorobutanoxy ligands (Fig. S1) (7), a sharp signal associated with physisorbed triethylboron formation $\left(\mathrm{BEt}_{3}\right)$ is observed after activation with $\mathrm{Et}_{3} \mathrm{Al}$ (Fig. S2). The addition of $\mathrm{Et}_{3} \mathrm{Al}$ also leads to the appearance of paramagnetic signals at ca. $-60 \mathrm{ppm}$ in the ${ }^{1} \mathrm{H}$ solid-state NMR spectra (25) of Ziegler-Natta catalysts prepared with or without $\mathrm{BCl}_{3}$ addition, that are likely related to the presence of $\mathrm{Ti}^{\mathrm{III}}$ species in their vicinity (Fig. S3). These paramagnetic signals are noticeably more pronounced in the spectra of the $\mathrm{BCl}_{3}$ treated samples (Fig. S3).

Consequently, we tried to identify these paramagnetic species by EPR spectroscopy at $10 \mathrm{~K}$ and 9.5 GHz on samples with different $\mathrm{BCl}_{3}$ loading, i.e. $\mathrm{B} / \mathrm{Ti}=0,2.60$ and 4.10 (Fig. 2b). These spectra reveal two paramagnetic species, characterized by a broad line around 340-390 mT and a narrower line at 320-340 $\mathrm{mT}$ that corresponds to an axially symmetric species. A species with a signal very similar to the 340-390 $\mathrm{mT}$ band has been observed before and has been assigned to $\mathrm{Ti}(\mathrm{III})$ surface species on $\mathrm{MgCl}_{2}$ (110) (26). Only the 320-340 $\mathrm{mT}$ band grows with increasing amount of added $\mathrm{BCl}_{3}$, but is already present as a weak signal without addition of $\mathrm{BCl}_{3}$ (see Fig. 2c and Fig. S4 - S6). Each of the three CW EPR spectra, shown in Fig. 2b, was fitted by a superposition of four individual spectra, revealing nearly the same $g$ tensor parameters for all samples (Table S3). Three mean sets of principal $g$ values contributing to the $340-390 \mathrm{mT}$ band

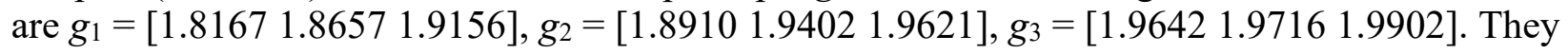
are consistent with previously estimated $g$ tensor parameters for the three different conformations of $\mathrm{TiCl}_{3}$ on the different $\mathrm{MgCl}_{2}$ surfaces (26).

We then focused on establishing the nature of the species with the nearly axially symmetric $g$ tensor $g_{4}=\left[\begin{array}{l}2.0023 \\ 2.00532 .1289\end{array}\right]$. Being larger than or similar to the free electron $g$ value $\left(g_{e}\right)$, these principal $g$ values are highly unusual for a Ti(III) species. On the other hand, the large $g$ anisotropy makes assignment to an organic radical very unlikely. The $g$ tensor with unexpectedly large principal values is reminiscent of a previous observation for the $3 \mathrm{~d}^{1} 3,10,17,24$ tetrasulphonatophthalocyanin (tspc) complex of V(IV)O, in particular, with its $g_{\|}>g_{e}(27)$, which indicates that the $g>g_{e}$ values for $\mathrm{d}^{1}$ species are indeed possible (see also SM $g$ tensor calculations). This, together with the large anisotropy, led us to attribute the observed species to a Ti(III) complex with a distinct electronic structure rather than to an organic radical. A similar species can be recognized as a weak contribution to Q-band EPR spectra that were obtained in previous work on catalysts that were not activated by $\mathrm{BCl}_{3}(26)$, but this species has not been 
further discussed. We found that it was strongly suppressed in $35.7 \mathrm{GHz}$ pulse EPR echo-detected spectra (Fig. S4), whereas it was readily observed in $9.5 \mathrm{GHz}$ echo-detected EPR spectra (Fig. 2c). Since strong suppression of the $\mathrm{TiCl}_{3}$ echo signals at $9.5 \mathrm{GHz}$ is beneficial for characterizing the $g>2$ species, further pulse EPR studies of the samples of $\mathrm{MgCl}_{2}$-supported Ziegler-Natta catalysts with different $\mathrm{BCl}_{3}$ loading were performed at this frequency (Fig. 2c). Like the CW EPR of this species, the echo-detected EPR signal, shown in Fig. 2c, continuously grew in intensity with increasing $\mathrm{BCl}_{3}$ loading and thus paralleled the increasing catalyst activity (Fig. 2a). Therefore, we identify this $g>2$ species (Fig. 2 b \& c, marked with arrows) as the active centers of $\mathrm{MgCl}_{2}$ supported Ziegler-Natta catalysts.

\section{Evaluation of structure of the active centers}

We further characterized this species by the 2D hyperfine spectroscopy technique HYSCORE (28). For these studies, we selected the sample with the highest activity of $38 \mathrm{~kg}_{\mathrm{PE}}\left(\mathrm{g}_{\mathrm{cat}} \mathrm{h}\right)^{-1}(\mathrm{~B} / \mathrm{Ti}=3$ and Table S1) because of the presence of the highest concentration of active centers. The HYSCORE spectrum was measured at the maximum of the $9.5 \mathrm{GHz}$ field-swept echo-detected EPR spectrum (Fig. 3a, marked with arrow).

HYSCORE spectroscopy (Fig. 3b) reveals the presence of ${ }^{1} \mathrm{H}$ and ${ }^{27} \mathrm{Al}$ nuclei, coupled to the paramagnetic center by magnetic hyperfine interaction. The experimental HYSCORE pattern was simulated by adjusting hyperfine and quadrupole coupling parameters (Fig. 3b, red). The estimated ${ }^{1} \mathrm{H}$ isotropic hyperfine coupling of $a_{\text {iso }}\left({ }^{1} \mathrm{H}\right)=-7.5 \pm 0.5 \mathrm{MHz}$ is, in fact, typical for the protons of alkyl ligands in $\mathrm{Ti}$ (III) alkyl complexes $(18,20)$. Within a point-dipole approximation we find a relatively large average $\mathrm{Ti} \cdots \mathrm{H}$ distance of $\mathrm{r}_{\mathrm{Ti}-\mathrm{H}}=3.16 \pm 0.24 \AA$, which suggests that only relatively weak $\alpha-$ or $\beta-\mathrm{H}$ agostic interactions are observed within the alkyl ligand(s) $(18,20)$. At the same time, the moderate ${ }^{27} \mathrm{Al}$ isotropic hyperfine coupling $\mathrm{a}_{\text {iso }}\left({ }^{27} \mathrm{Al}\right)=1.5 \pm 0.2 \mathrm{MHz}$ indicates that the $\mathrm{Al}$ atom is in a proximity to the paramagnetic center, most likely being connected to it through one bridging atom (see SM Evaluation of the structure of the active species). Strong ${ }^{27} \mathrm{Al}$ quadrupole coupling $\mathrm{Q}\left({ }^{27} \mathrm{Al}\right)=-42 \pm 1 \mathrm{MHz}$ indicates low symmetry of the $\mathrm{Al}$ coordination geometry. No ${ }^{11} \mathrm{~B}$ hyperfine couplings were observed in the HYSCORE spectra. This is consistent with the absence of any modifications of the active center upon $\mathrm{BCl}_{3}$ addition that can be inferred from the similar features of the produced polyethylenes as previously mentioned (24), from the removal of B in the form of $\mathrm{BEt}_{3}$ and from the unchanged $g$ tensor principal values. The EPR data also agrees with the NMR data discussed above, namely the observation of ${ }^{1} \mathrm{H}$ paramagnetic NMR resonances (Fig. S3). Very importantly, all these materials with characteristic EPR Ti(III)-alkyl signatures are active in polymerization by sole addition of ethylene monomer (see Table S2). These EPR spectroscopic signatures are thus assigned to active centers.

Based on these conclusions, we performed a search through possible DFT models, including Ti(III) alkyls, bridging alkyls and alkoxides with various ways of coordination of indicated organometallic ligands and aluminum alkyls (Fig. S8 - S11). Among all the tested models, we found only one (Fig. 3c \& S11, a), that provides DFT-calculated ${ }^{1} \mathrm{H}$ hyperfine couplings for all $\mathrm{H}$ atoms of the Ti- $\mathrm{C}_{2} \mathrm{H}_{5}$ ligand that are in line with the experimental ${ }^{1} \mathrm{H}$ HYSCORE pattern (Figs. $3 \mathrm{~d}$ $\& \mathrm{~S} 11, \mathrm{~b}-\mathrm{f})$, together with a reasonable fit of the DFT-computed ${ }^{27} \mathrm{Al}$ couplings to the ones observed experimentally (Table S4). As ${ }^{1} \mathrm{H}$ hyperfine couplings were previously found to act as fingerprints of the conformations of Ti(III) alkyl complexes $(18,20)$, we propose the structure, shown in Fig. 3c, as an active center of the Ziegler-Natta catalysts. Being essentially a Ti(III) metal-alkyl complex of a formula $\left[\mathrm{Ti}\left(\mathrm{C}_{2} \mathrm{H}_{5}\right) \mathrm{Cl}_{2}-(\mu-\mathrm{Cl})-\mathrm{Al}\left(\mathrm{C}_{2} \mathrm{H}_{5}\right)_{2}\right] @ \mathrm{MgCl}_{2}(\mathrm{Fig}$. 3c), this structure is in fact in line with the original proposal of Giulio Natta regarding the active site of Ziegler-Natta 
catalysts (21). With a calculated Ti-C-H angle of $98.64^{\circ}$, it displays an $\alpha-\mathrm{H}$ agostic interaction. The $\mathrm{Al}$ atom is essentially tris-coordinated, except for a weak $\mathrm{Al}-\mathrm{H}$ interaction $(2.183 \AA$ distance) with the $\beta-\mathrm{H}$ atom of $\mathrm{Ti}-\mathrm{C}_{2} \mathrm{H}_{5}$ ligand. A similar structure of $\left[\mathrm{Ti}_{2}\left(\mathrm{C}_{2} \mathrm{H}_{5}\right) \mathrm{Cl}_{2}-(\mu-\mathrm{Cl})-(\mu-\mathrm{C})-\right.$ $\left.\mathrm{Al}\left(\mathrm{C}_{2} \mathrm{H}_{5}\right)_{2}\right] @ \mathrm{MgCl}_{2}\left(\mathbf{C}\right.$, Fig. 1a \& Fig. S9, b), which has the $\alpha-\mathrm{C}$ atom of Ti- $\mathrm{C}_{2} \mathrm{H}_{5}$ ligand bridging between the Ti and $\mathrm{Al}$ atoms, is calculated to be slightly more stable by $4.0 \mathrm{kcal} \cdot \mathrm{mol}^{-1}$ according to the DFT computation, but exhibits a strong mismatch between DFT-computed ${ }^{1} \mathrm{H}$ hyperfine couplings and the experimental HYSCORE spectrum (see Fig. S9, b). The former is likely more favorable experimentally due to specific local environments that are not included in our cluster model that was used to allow accurate EPR calculation but only takes into account the first coordination environment.

Having also a weak $\pi$ character in the Ti-C bond, revealed by a deviation of the natural hybrid orbital $(\mathrm{NHO})$ on carbon from the Ti-C axis $\left(\Theta_{\mathrm{NHO}-\mathrm{C}-\mathrm{Ti}}=9.0^{\circ}\right)$, the evaluated structure of the active species (Fig. 3c \& Fig. S11, a) is akin to $\beta$-diiminato Ti(III) alkyls, which were shown to participate in ethylene polymerization in the absence of co-activator (18). Such $\pi$ character, being likely enhanced after ethylene coordination, favors ethylene insertion into the Ti-C bond, while electron transfer of unpaired electron density from SOMO to the $\pi^{*}\left(\mathrm{C}_{2} \mathrm{H}_{4}\right)$ orbital lowers the formation energy of $\pi$-ethylene complexes in $\mathrm{d}^{1}$ metal alkyls (18). These factors make Ti(III) $\mathrm{d}^{1}$ alkyl complexes efficient ethylene polymerization catalysts, which supports our proposition of $\left[\mathrm{Ti}\left(\mathrm{C}_{2} \mathrm{H}_{5}\right) \mathrm{Cl}_{2}-(\mu-\mathrm{Cl})-\mathrm{Al}\left(\mathrm{C}_{2} \mathrm{H}_{5}\right)_{2}\right] @ \mathrm{MgCl}_{2}$ species (Fig. 3c) to be the active centers of the ZieglerNatta catalysts that become the active sites for polymerization in the presence of ethylene. 
a)
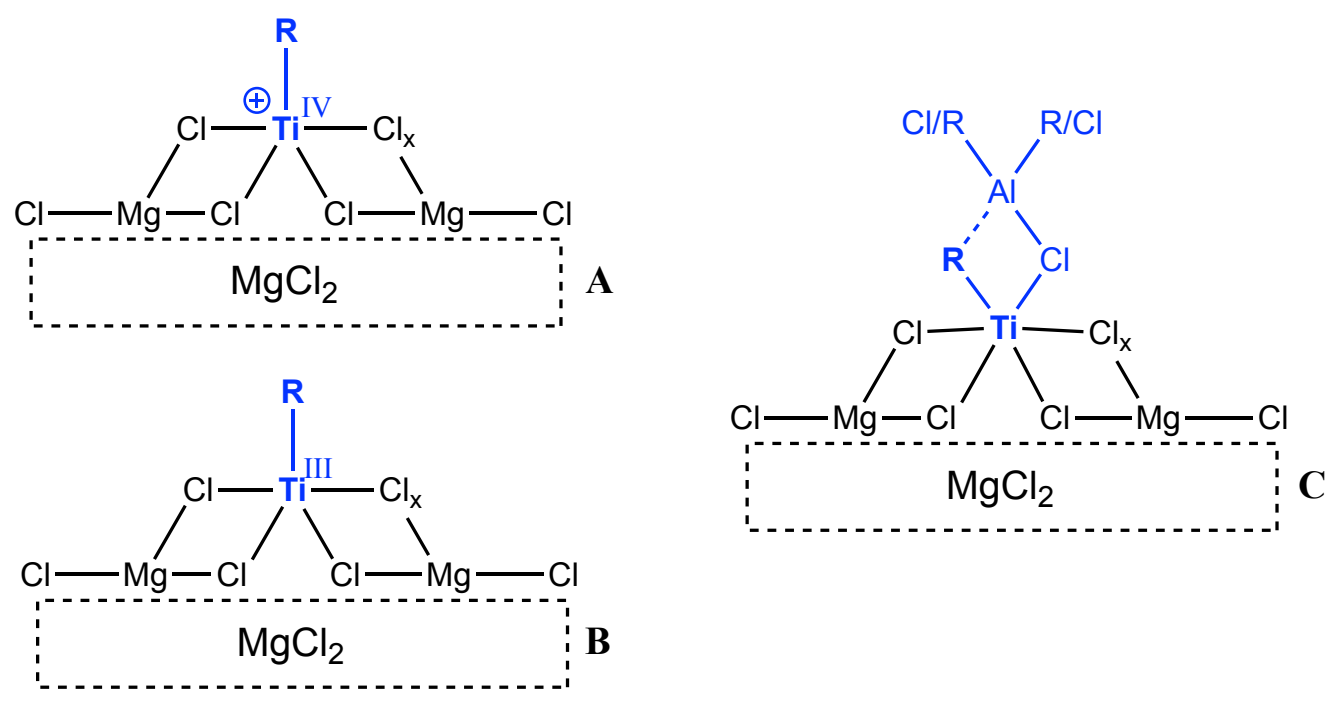

b)

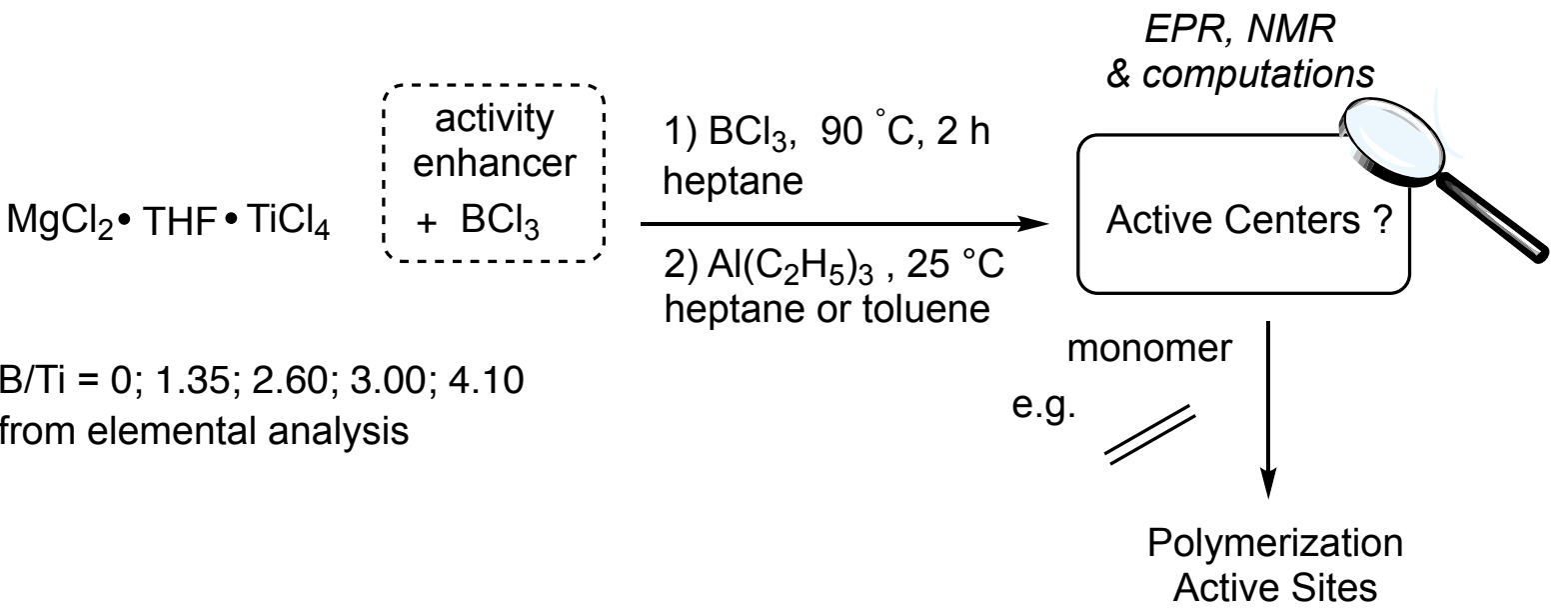

Figure 1. a) Possible active centers A-C of $\mathrm{MgCl}_{2}$-supported Ziegler-Natta ethylene polymerization catalysts. b) Preparation of $\mathrm{MgCl}_{2}$-supported Ziegler-Natta catalysts for ethylene polymerization as studied in the present work. 
a)

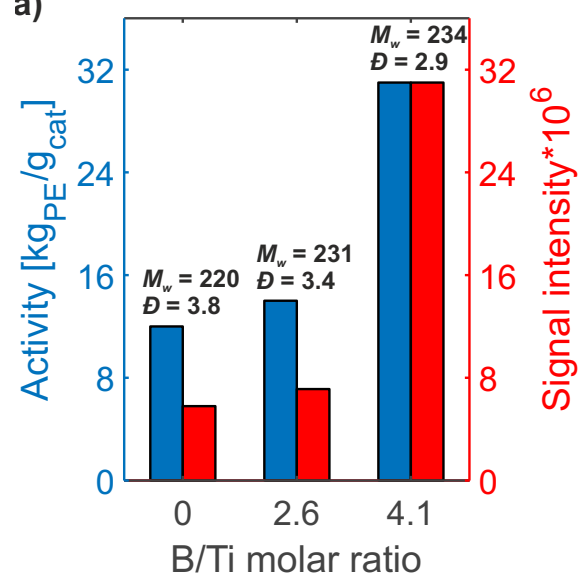

b)

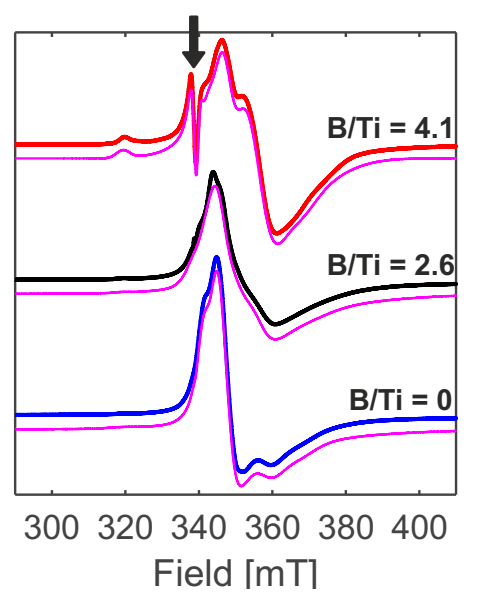

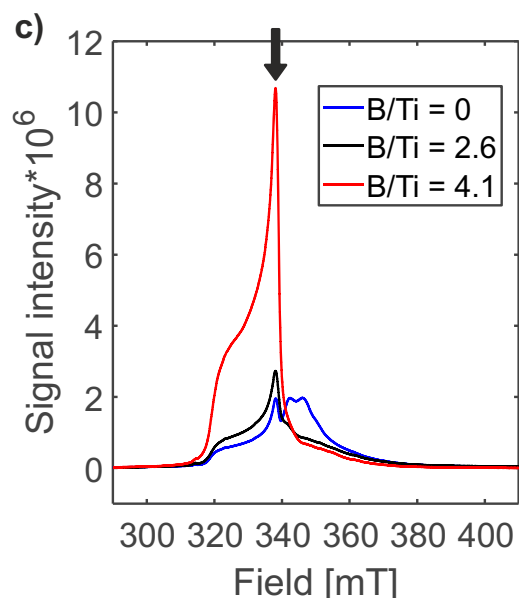

Figure 2. a) Change of activities towards ethylene polymerization (blue, right scale) and $9.5 \mathrm{GHz}$ echodetected EPR signal intensities (red, left scale) of Ziegler-Natta catalysts with a change of B/Ti ratio. For each catalyst, the average molar mass $M_{\mathrm{w}}\left[\mathrm{kg} \mathrm{mol}^{-1}\right]$ and the dispersity $Ð=M_{\mathrm{w}} / M_{\mathrm{n}}$ of produced polyethylene are indicated. EPR signal intensities are measured at the field positions, marked with arrow in c), and normalized by the ratio of activity to intensity for the catalyst with $\mathrm{B} / \mathrm{Ti}=4.1$. b) $9.5 \mathrm{GHz} \mathrm{CW}$ EPR spectra of Ziegler-Natta catalysts with $\mathrm{B} / \mathrm{Ti}=0$ (blue), $\mathrm{B} / \mathrm{Ti}=2.6$ (black) and $\mathrm{B} / \mathrm{Ti}=4.1$ (red), together with the simulations (violet) of all the shown spectra (see text for parameters of the simulations). c) $9.5 \mathrm{GHz}$ echodetected EPR spectra of Ziegler-Natta catalysts with $\mathrm{B} / \mathrm{Ti}=0$ (blue), $\mathrm{B} / \mathrm{Ti}=2.6$ (black) and $\mathrm{B} / \mathrm{Ti}=4.1$ (red). The signal that grows with increasing amount of added $\mathrm{BCl}_{3}$ is indicated with arrows in $\mathrm{b}$ ) and c). 

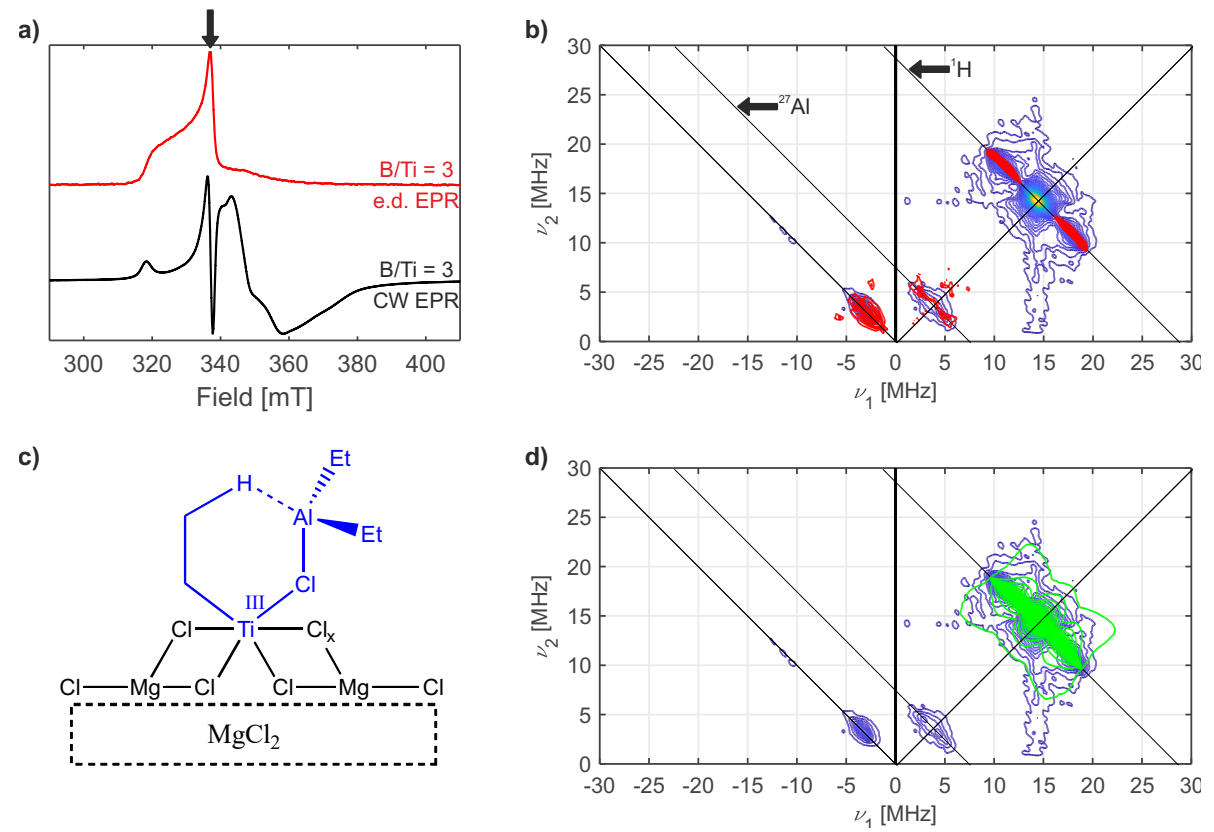

Figure 3. a) $9.5 \mathrm{GHz}$ CW (black) and echo-detected (red) EPR spectra of Ziegler-Natta catalyst with B/Ti $=3$. b) Experimental $9.5 \mathrm{GHz}$ HYSCORE spectrum of Ziegler-Natta catalyst with $\mathrm{B} / \mathrm{Ti}=3, \tau=$ [128 160 192] ns (blue to yellow), together with its simulation (red). c) Proposed structure of the active center of heterogeneous Ziegler-Natta catalysts (see also Fig. S11, a). d) Experimental HYSCORE spectrum of Ziegler-Natta catalyst with $\mathrm{B} / \mathrm{Ti}=3$ (blue) and a simulation of experimental ${ }^{1} \mathrm{H}$ hyperfine couplings (green), based on DFT calculations on the proposed structure (see text \& Fig. S11, b - f). The experimental HYSCORE spectrum (see Fig. S7) was measured at the magnetic field position indicated by an arrow in a).

Acknowledgments: We acknowledge Olivier Boyron, Manel Taam and Edgar Espinosa (Université de Lyon) for SEC analyses and Rene Tschaggelar (ETH Zürich) for the technical support in EPR experiments. Funding: A.A. is supported by a SNF-ANR grant (Mr. CAT 277275-15). M.H. is supported by a ANR-SNF grant (MRCAT ANR-15-CE29-0025) Author contributions: A.A. and M.H. declare equal contribution. A.A. performed EPR spectroscopy and DFT computations. M.H. carried out the synthesis of the catalysts and evaluated the polymerization activity studies. J. B and M. H. performed NMR measurements. S.N., D.G., K.S and D.K. supervised the project. C.C., G.J., J. R., V.M., A.L. and G.P. coordinated the project and provided guidance. All authors participated in writing the final manuscript. Competing interests: Authors declare no competing interests. Data and materials availability: All data is available in the main text or the supplementary materials.

\section{References:}

1. K. Singh, "Chemistry, Economics and Politics" in Chemistry in Daily Life (PHI Learning Pvt. Ltd., Delhi, 2012), pp. 132-134.

2. R. Geyer, J. R. Jambeck, K. L. Law, Production, use, and fate of all plastics ever made. Sci. $A d v .3$ (7), e1700782 (2017). 
3. K. Ziegler, E. Holzkamp, H. Breil, H. Martin, Das Mülheimer Normaldruck-PolyäthylenVerfahren. Angew. Chem. 67, 541-547 (1955).

4. G. Natta, Kinetic studies of $\alpha$-olefin polymerization. J. Polym. Sci. 34 (127), 21-48 (1959).

5. N. Kashiwa, The discovery and progress of $\mathrm{MgCl}_{2}$-supported $\mathrm{TiCl}_{4}$ catalysts. J. Polym. Sci. Part $A 42$ (1), 1-8 (2004).

6. G. Cecchin, G. Morini, F. Piemontesi, "Ziegler-Natta catalysts" in Kirk-Othmer Encyclopedia of Chemical Technology (J. Wiley \& Sons, New York, 2003), pp. 502-554.

7. E. Grau, A. Lesage, S. Norsic, C. Copéret, V. Monteil, P. Sautet, Tetrahydrofuran in $\mathrm{TiCl}_{4} / \mathrm{THF} / \mathrm{MgCl}_{2}$ : a Non-Innocent Ligand for Supported Ziegler-Natta Polymerization Catalysts. ACS Catal. 3 (1), 52-56 (2013).

8. E. J. Arlman, P. Cossee, Ziegler-Natta catalysis III. Stereospecific polymerization of propene with the catalyst system $\mathrm{TiCl}_{3}-\mathrm{AlEt}_{3}$. J. Catal. 3 (1), 99-104 (1964).

9. W. Kaminsky, Highly active metallocene catalysts for olefin polymerization. J. Chem. Soc. 9, 1413-1418 (1998).

10. R. F. Jordan, W. E. Dasher, S. F. Echols, Reactive cationic dicyclopentadienyl zirconium(IV) complexes. J. Am. Chem. Soc. 108 (7), 1718-1719 (1986).

11. T. J. Marks, Surface-Bound Metal Hydrocarbyls. Organometallic Connections between Heterogeneous and Homogeneous Catalysis. Acc. Chem. Res. 25 (2), $57-65$ (1992).

12. O. Olabisi, M. Atiqullah, W. Kaminsky, Group 4 Metallocenes: Supported and Unsupported. J. Marcomol. Sci. Polymer Rev. 37 (3), 519-554 (1997).

13. R. F. Jordan, Cationic Metal-Alkyl Olefin Polymerization Catalysts. J. Chem. Educ. 65 (4), 285-289 (1988).

14. Yu. V. Kissin, Active centers in Ziegler-Natta catalysts: Formation kinetics and structure. $J$. Catal. 292, 188-200 (2012).

15. D. Fregonese, S. Mortara, S. Bresadola, Ziegler-Natta $\mathrm{MgCl}_{2}$-supported catalysts: relationship between titanium oxidation states distribution and activity in olefin polymerization. $J$. Mol. Catal. A: Chemical 172 (1-2), 89-95 (2001).

16. E. I. Koshevoy, T. B. Mikenas, V. A. Zakharov, A. M. Volodin, R. M. Kenzhin, Formation of isolated titanium(III) ions in superactive titanium-magnesium catalysts with a low titanium content as active sites in ethylene polymerization. Catal. Comm. 48, 38-40 (2014).

17. E. I. Koshevoy, T. B. Mikenas, V. A. Zakharov, A. A. Shubin, A. A. Barabanov, Electron Paramagnetic Resonance Study of the Interaction of Surface Titanium Species with $\mathrm{AlR}_{3}$ Cocatalyst in Supported Ziegler-Natta Catalysts with a Low Titanium Content. J. Phys. Chem. C 120 (2), 1121-1129 (2016).

18. A. Ashuiev et al., https://chemrxiv.org/ndownloader/files/24060725 
19. V. A. Zakharov, Yu. I. Yermakov, Supported Organometallic Catalysts for Olefin Polymerization. Catal. Rev. Sci. Eng. 19, 67-103 (1979).

20. F. Allouche, D. Klose, C. P. Gordon, A. Ashuiev, M. Wörle, V. Kalendra, V. Mougel, C. Copéret, G. Jeschke, Low-Coordinated Ti(III) Alkyl-Molecular and Surface-Complexes: Detailed Structure from Advanced EPR Spectroscopy. Angew. Chem. Int. Ed. 57 (44), 1453314537 (2018).

21. G. Natta, P. Pino, G. Mazzanti, U. Gianini, A crystallizable organometallic complex containing titanium and aluminium. J. Am. Chem. Soc. 79 (11), 2975-2976 (1957).

22. L. A. M. Rodriguez, H. M. Van Looy, Studies on Ziegler-Natta catalysts. Part V. Stereospecificity of the active center. J. Polym. Sci.: Part A-1, 4, 1971-1992 (1966).

23. D. Ribour, V. Monteil, R. Spitz. Strong activation of $\mathrm{MgCl}_{2}$-supported Ziegler-Natta catalysts by treatments with $\mathrm{BCl}_{3}$ : Evidence and application of the "cluster" model of active sites. $J$. Polym. Sci. Part A 47, 5784-5791 (2009).

24. M. Humbert, S. Norsic, J. Raynaud, V. Monteil, Activity enhancement of $\mathrm{MgCl}_{2}$-supported Ziegler-Natta catalysts by Lewis-Acid pre-treatment for ethylene polymerization. Chinese J. Polym. Sci. 37, 1031-1038 (2019).

25. A. J. Pell, G. Pintacuda, C. P. Grey, Paramagnetic NMR in solution and the solid state. Prog. Nucl. Mag. Res. Sp. 111, 1-271 (2019).

26. E. Morra, E. Giamello, S. Van Doorslaer, G. Antinucci, M. D'Amore, V. Busico, M. Chiesa, Probing the Coordinative Unsaturation and Local Environment of $\mathrm{Ti}^{3+}$ Sites in an Activated High-Yield Ziegler-Natta Catalyst. Angew. Chem. Int. Ed. 54 (16), 4857-4860 (2015).

27. A. Skorobogaty, R. Lancashire, T. D. Smith, J. R. Pilbrow, G. R. Sinclaire, Optical and Electron Spin Resonance Studies of Copper(II), Nickel(II) and Oxovanadium(IV) Complexes of Water-soluble Phthalocyanine and Porphyrazine Chelates Absorbed on Sephadex Resins, and the Effect of Added Dithionite. J. Chem. Soc., Faraday Trans. 2 79, 1123-1141 (1983).

28. P. Höfer, A. Grupp, H. Nebenführ, M. Mehring, Hyperfine sublevel correlation (hyscore) spectroscopy: a 2D ESR investigation of the squaric acid radical. Chem. Phys. Lett. 132 (3), 279-282 (1986). 


\section{Supplementary Materials for}

Spectroscopic Signature and Structure of Active Centers in Ziegler-Natta Polymerization Catalysts revealed by Electron Paramagnetic Resonance
A. Ashuiev, M. Humbert, S. Norsic, J. Blahut, D. Gajan, K. Searles, D. Klose, A. Lesage, G. Pintacuda, J. Raynaud, V. Monteil, C. Copéret, G. Jeschke
Correspondence to: jean.raynaud@univ-lyon1.fr; vincent.monteil@univ-lyon1.fr; ccoperet@inorg.chem.ethz.ch; gunnar.jeschke@phys.chem.ethz.ch

\section{This file includes:}

Materials and Methods

Supplementary Text

Figures $\mathrm{S} 1$ to $\mathrm{S} 11$

Tables S1 to S4

References 


\section{Materials and Methods}

All experiments were carried out under inert conditions.

Synthesis of heterogeneous Ziegler-Natta catalysts

The $\mathrm{MgCl}_{2}$ THF support was prepared by stirring $\mathrm{MgCl}_{2}$ in boiling THF (with a ratio of $1 \mathrm{~g}$ per $7 \mathrm{~mL}$ of solvent) for $4 \mathrm{~h}$. Heptane was added to the mixture and the precipitating/recrystallizing solid was washed three times with heptane and dried under vacuum at $90{ }^{\circ} \mathrm{C}$ for $1 \mathrm{~h}$ to yield a white solid corresponding to $\mathrm{MgCl}_{2}$ (THF) 1.5 (or "activated support"). The elemental analysis of the $\mathrm{MgCl}_{2}$ THF support showed that no traces of $\mathrm{B}$ were introduced before the treatment using the described procedure (vide infra).

The $\mathrm{MgCl}_{2}$ THF support was immersed in pure $\mathrm{TiCl}_{4}$ and the mixture was heated at $90^{\circ} \mathrm{C}$ during 4 hours under stirring. Afterwards, three steps of hot toluene washings, one step of hot 1,2dichloroethane washing and one step of heptane washing at room temperature were realized. Then, a second treatment with diluted $\mathrm{TiCl}_{4}$ in heptane was performed for $2 \mathrm{~h}$ at $90{ }^{\circ} \mathrm{C}$, followed by several washings in heptane (min. 3) at room temperature in order to remove $\mathrm{TiCl}_{4}$ excess.

For the catalysts modified with $\mathrm{BCl}_{3}$, these steps were followed by introduction of different amounts of $1 \mathrm{M}$ solution of $\mathrm{BCl}_{3}$ in heptane to the previously obtained solid, heating to $90^{\circ} \mathrm{C}$ during 1 hour under stirring and three steps of washing with heptane. After drying under vacuum, the obtained samples were kept under inert atmosphere (glovebox).

The $\mathrm{BCl}_{3}$ loading of all the prepared samples, verified by the elemental analysis, together with their activities towards ethylene polymerization and the parameters of produced polyethylene, are shown in Table $\mathrm{S} 1$. The samples with $\mathrm{B} / \mathrm{Ti}=0, \mathrm{~B} / \mathrm{Ti}=2.60$ and $\mathrm{B} / \mathrm{Ti}=4.10$, used in quantitative pulse EPR measurements, were prepared from the same original batch, while all the other samples were prepared independently. In particular sample with B/Ti $=3$ (see Table S1) shows the good reproducibility of the inorganic synthesis. Since its [Ti] content was slightly higher than that of $\mathrm{B} / \mathrm{Ti}=4.10$ for instance, it explains that it displayed the highest activity by weight of all tested catalysts and thus the highest corresponding characteristic signal intensity in EPR spectroscopy.

All elemental analyses were done by Mikroanalytischen Laboratorium Kolbe in Oberhausen (Germany).

\section{Synthesis of polyethylenes}

5-10 $\mathrm{mg}$ of precatalyst (a precise mass was used) was added to a $1 \mathrm{~L}$ flask containing a 400 $\mathrm{mL}$ volume of a $3 \mathrm{mmol} \cdot \mathrm{L}^{-1} \mathrm{Et}_{3} \mathrm{Al}$ solution in heptane under Ar atmosphere. The mixture was then transferred to a $1 \mathrm{~L}$-autoclave reactor. The ratio Al/Ti varied between 100 and 400 in these experiments. After that, 1 bar of dihydrogen and then 6 bar of ethylene were subsequently added in the reactor and the polymerization was performed at $80^{\circ} \mathrm{C}$. Polymerizations were stopped after a 5-bar consumption of ethylene from the $2 \mathrm{~L}$ ballast that feeds the reactor corresponding to about $30 \mathrm{~g}$ of polyethylene, which we consistently verified gravimetrically. The obtained polymer, already precipitated after the slurry polymerization, was washed with methanol and filtered through sintered glass.

All activities were calculated by measuring ethylene consumption during time using Van der Waals' cubic state equation.

SEC: Molar masses $\left(M_{\mathrm{w}}\right.$ and $\left.Ð\right)$ of the polyethylenes were determined by size exclusion chromatography (SEC) with a Viscotek system (Malvern Instruments, Malvern, UK) equipped 
with three columns (Polefin $300 \mathrm{~mm} \times 8 \mathrm{~mm}$ I. D. from Polymer Standards Service, porosity of 1 000, 100000 and $1000000 \AA$ ). Sample solutions of $1 \mathrm{mg} \cdot \mathrm{mL}^{-1}$ were eluted in $1,2,4-$ trichlorobenzene using a flow rate of $1 \mathrm{~mL} \cdot \mathrm{min}^{-1}$ at $150{ }^{\circ} \mathrm{C}$. The mobile phase was stabilized with 2,6-di(tert-butyl)-4-methylphenol. Three detectors were used: viscosimeter, refractometer and Light Scattering detector. The system was calibrated with polystyrene standards using triple calibration.

Sample preparation for NMR studies

For ${ }^{11} \mathrm{~B}$ NMR studies of the samples before the addition of Et $3 \mathrm{Al}$ ("precatalysts", Fig. S1), the solid powder of the precatalysts was used as it was.

For ${ }^{1} \mathrm{H}$ and ${ }^{11} \mathrm{~B}$ NMR studies of the samples after the addition of co-catalyst $\mathrm{Et}_{3} \mathrm{Al}$ (Figs. S2 \& S3), all the samples were activated with $1 \mathrm{M}$ solution of $\mathrm{Et}_{3} \mathrm{Al}$ in $\mathrm{C}_{6} \mathrm{D}_{6}$ with a ratio $\mathrm{Al} / \mathrm{Ti}=10$. Two samples were studied: one in the absence of $\mathrm{BCl}_{3}$ (no $\mathrm{BCl}_{3}$ treatment, Table $\mathrm{S} 1$, entry 1) and one with a ratio $\mathrm{B} / \mathrm{Ti}=1.35$ (Table $\mathrm{S} 1$, entry 2 ). The obtained "pasty" suspensions were merely filtered with the aim of reaching powder samples which were directly inserted in a $1.3 \mathrm{~mm}$ zirconium-oxide rotor. All these stages were performed in a glovebox.

Validation of Spectroscopic Methodology: Polymerization performances of alkylated NMR samples

The two samples (Table S1, entry 1 and 2) were activated in a glovebox with 1 M solution of $\mathrm{Et}_{3} \mathrm{Al}$ in $\mathrm{C}_{6} \mathrm{D}_{6}$ with $\mathrm{Al} / \mathrm{Ti}=10$. The thus-obtained suspensions were quickly filtered with the aim of obtaining activated powders. The resulting pasty solids were directly added to heptane solution (to recover a classical suspension for a catalytic heterogeneous polymerization of ethylene) with $\mathrm{Et}_{3} \mathrm{Al}$ (concentration of $3 \mathrm{mmol} / \mathrm{L}$ ) to match the standard value of $100<\mathrm{Al} / \mathrm{Ti}<$ 400 ) or without $\mathrm{Et}_{3} \mathrm{Al}$ (to verify the hypothesis that active centers observed spectroscopically turn to polymerization active sites by sole addition of ethylene monomer) and tested in polyethylene synthesis. Standard ethylene polymerization conditions were used with or without $\mathrm{H}_{2}$ addition. Activities were on par with expectations from Ziegler-Natta samples and are listed in Table S2-a.

\section{Paramagnetic NMR measurements}

All experiments were carried out on a wide-bore Bruker Advance III with a ${ }^{1} \mathrm{H}$ Larmor frequency of $500 \mathrm{MHz}$ using a double-resonance $1.3 \mathrm{~mm}$ probe at a spinning frequency of $60 \mathrm{kHz}$. Probe temperature was controlled with a Bruker BCU II unit to $270 \mathrm{~K}$, which corresponds to a temperature of $\sim 315 \mathrm{~K}$ inside the sample due to frictional heating. Ultra-dry, oxygen-free nitrogen obtained by evaporation of liquid nitrogen was used for sample spinning and temperature regulation.

${ }^{1} \mathrm{H}$ chemical shifts were referenced to the single resonance observed for protons in adamantane at $1.8 \mathrm{ppm}$ with respect to the signal for neat tetramethylsilane (TMS).

The ${ }^{1} \mathrm{H}$ NMR spectrum of the sample without $\mathrm{BCl}_{3}(\mathrm{~B} / \mathrm{Ti}=0)$ after $\mathrm{Et}_{3} \mathrm{Al}$ addition (Fig. S3, a) was acquired with a saturation-recovery pulse sequence, using a $5 \mathrm{~ms}$ delay between the train of saturation pulses and the read pulse. A rotor-synchronized spin-echo period of total length two times $16.67 \mu \mathrm{s}$ was inserted before acquisition. The proton pulses were applied at a RF field of $200 \mathrm{kHz}$. A total of 131072 scans were accumulated.

The ${ }^{1} \mathrm{H}$ NMR spectrum for the sample with $\mathrm{BCl}_{3}(\mathrm{~B} / \mathrm{Ti}=1.35)$ after $\mathrm{Et}_{3} \mathrm{Al}$ addition (Fig. S3, b) was acquired with a saturation-recovery pulse sequence, using a $1 \mathrm{~ms}$ delay between the train of saturation pulses and the read pulse. A rotor-synchronized spin-echo period of total length two 
times $16.67 \mu$ s was inserted before acquisition. The proton pulses were applied at a RF field of $250 \mathrm{kHz}$. A total of 40960 scans were accumulated.

${ }^{11} \mathrm{~B}$ NMR spectroscopy

The chemical shift was referenced to the single resonance observed for $\mathrm{B}(\mathrm{OH})_{3}$ in solution at $19.6 \mathrm{ppm}$.

The ${ }^{11} \mathrm{~B}$ NMR spectrum for the precatalyst with $\mathrm{BCl}_{3}(\mathrm{~B} / \mathrm{Ti}=1.35$, Fig. S1) was acquired with a direct excitation pulse sequence, composed of a $90^{\circ}$ excitation pulse followed by a rotorsynchronized spin-echo period of total length two times $16.67 \mu \mathrm{s}$. During acquisition heteronuclear proton decoupling was applied at a $100 \mathrm{kHz}$ RF field strength. A total of 5120 scans were accumulated. The RF field for the $180^{\circ}{ }^{11} \mathrm{~B}$ pulse was $25 \mathrm{kHz}$.

The $2 \mathrm{D}{ }^{11} \mathrm{~B}-{ }^{11} \mathrm{~B}$ MQMAS spectrum was recorded with $256 t_{1}$ increments $40 \mu \mathrm{s}$, each with 240 scans. The RF field was $270 \mathrm{kHz}$ for excitation and conversion pulses, and $10 \mathrm{kHz}$ for the $90^{\circ}$ selective pulse.

The ${ }^{11} \mathrm{~B}$ NMR spectrum for the sample with $\mathrm{BCl}_{3}(\mathrm{~B} / \mathrm{Ti}=1.35)$ after $\mathrm{Et}_{3} \mathrm{Al}$ addition (Fig. S2) was acquired with a direct excitation pulse sequence, composed of a $90^{\circ}$ excitation pulse followed by a rotor-synchronized spin-echo period of total length two times $16.67 \mu \mathrm{s}$.. A total 20480 scans were accumulated. The RF field for the $180^{\circ}{ }^{11} \mathrm{~B}$ pulse was $344 \mathrm{kHz}$, and no proton decoupling was applied during signal acquisition.

\section{Sample preparation for EPR studies}

All samples for EPR spectroscopy were prepared in quartz tubes. The solid powders ( 40-50 $\mathrm{mg}$ ) of the catalysts were put into the EPR tubes inside the glovebox, filling the tubes up to 1.5 $2.5 \mathrm{~cm}$ height. The co-catalyst $\mathrm{Et}_{3} \mathrm{Al}$ was added to the solid powders of the catalysts directly in EPR tubes inside the glovebox as a $1 \mathrm{M}$ toluene solution. Toluene was used for its good glassforming abilities; it was purified using double semi-permeable surface (SPS) alumina columns (MBraun, Garching, Germany), and was degassed using three freeze-pump-thaw cycles before being used. For all samples, the $\mathrm{Et}_{3} \mathrm{Al}$ was added in the quantities enough to grant its molar excess towards Ti (5-10:1). Afterwards, all EPR tubes were flame-sealed under high vacuum conditions $\left(10^{-5}\right.$ mbar) while having the catalyst and the solvent frozen in liquid $\mathrm{N}_{2}$. The sealed EPR tubes were centrifuged and were frozen in liquid $\mathrm{N}_{2}$ several times in order to remove gas bubbles from the solid part of the sample. All the samples were prepared in the indicated way directly before the EPR measurement; the general time between the activation with $\mathrm{Et}_{3} \mathrm{Al}$ and the beginning of EPR measurements was around 20 minutes. A special procedure of sample preparation for the quantitative EPR measurements was applied (vide infra).

Validation of Spectroscopic Methodology: Polymerization performances of alkylated EPR samples

The two samples (Table S1, entry 1 and 5) were activated in a glovebox with 1 M solution of $\mathrm{Et}_{3} \mathrm{Al}$ in toluene with $\mathrm{Al} / \mathrm{Ti}=7$. The obtained suspensions were directly added to a heptane solution either with $\mathrm{Et}_{3} \mathrm{Al}$ (concentration of $3 \mathrm{mmol} / \mathrm{L}$ ) to match the standard value of $100<\mathrm{Al} / \mathrm{Ti}$ $<400$ ) or without $\mathrm{Et}_{3} \mathrm{Al}$ to verify the hypothesis that active centers observed spectroscopically turn to polymerization active sites by sole addition of ethylene monomer. Both samples were tested in polyethylene synthesis. Standard ethylene polymerization conditions were used with or without $\mathrm{H}_{2}$ addition. Activities were on par with expectations from Ziegler-Natta samples and are listed in Table S2-b. 


\section{$\underline{\mathrm{CW}} \underline{\mathrm{EPR}} \underline{\text { measurements }}$}

All CW EPR spectra were recorded at the temperature of $10 \mathrm{~K}$ at Bruker Elexsys E680 EPR spectrometer, equipped with helium flow cryostats ESR900 (Oxford Instruments, Oxfordshire, UK). CW measurements were performed using a Bruker SHQ resonator, with a modulation amplitude of $0.1 \mathrm{mT}$ (Fig. 2b \& Fig. S5) or $0.4 \mathrm{mT}$ (Fig. 3a) and modulation frequency of 100 $\mathrm{kHz}$. The lock-in amplifier time constant and conversion time were set to $81.92 \mathrm{~ms}$ and $327.68 \mathrm{~ms}$, respectively (Fig. 2b \& Fig. S5) or $81.92 \mathrm{~ms}$ and $167.77 \mathrm{~ms}$, respectively (Fig. 3a). The correction of the magnetic field offset was done using DPPH (Sigma-Aldrich, Buchs, Switzerland) as a standard.

Field values of all the spectra, shown on Fig. 2b, are normalized by the microwave frequency ratios. The intensities of all shown spectra are normalized by the values of their double integrals for qualitative illustration of the change in the $\mathrm{CW} E P R$ spectra with $\mathrm{BCl}_{3}$ addition. Field values of CW EPR spectrum of the catalyst with $\mathrm{B} / \mathrm{Ti}=3$ (Fig. 3a, black) are corrected by the microwave frequency ratio in order to match the echo-detected EPR spectrum (Fig. 3a, red).

\section{Analysis of EPR spectra}

Experimental EPR spectra were analyzed in a first step by global least squares fitting of all three CW EPR spectra (Fig. 2b) together with the echo-detected EPR spectrum of the sample with $\mathrm{B} / \mathrm{Ti}=4.10$ (Fig. 2c, red), using the EasySpin toolbox (1). Additional estimates for the $g$ tensor principal values of all three $\mathrm{TiCl}_{3}$ species and of the active species were estimated via least square fitting of individual CW EPR spectra in EasySpin (1). The final set of $g$ tensor parameters of the active species was obtained from the fit of $9.5 \mathrm{GHz}$ echo-detected EPR spectrum of the sample of Ziegler-Natta catalyst with $\mathrm{B} / \mathrm{Ti}=4.1$ (Fig. S5, a). For the $g$ tensor parameters of the $\mathrm{TiCl}_{3}$ species we report average values, estimated from independent least square fits of all three CW EPR spectra (Fig. S5, b-d). For these final fits, the $g$ tensor parameters of the active species were fixed to the values obtained from the fit of the echo-detected EPR spectrum. Because of the low relative weight of the active species in the CW EPR spectra such stabilization of the fits is beneficial. The $g$ tensor parameters of all the species present in CW EPR spectra are summarized in Table S3.

\subsection{GHz echo-detected EPR measurements}

All 9.5 GHz echo-detected EPR spectra were recorded at a temperature of $10 \mathrm{~K}$ with a Bruker Elexsys E680 EPR spectrometer, using a Bruker MS3 split-ring resonator. All the spectra were recorded using a standard 2-pulse sequence $\pi / 2-\tau-\pi-\tau$ - echo; the power of microwave pulses was set up for pulse lengths $\mathrm{t}_{\pi / 2}=16 \mathrm{~ns}, \mathrm{t}_{\pi}=32 \mathrm{~ns}$ by observing the inversion of electronic magnetization in Rabi oscillations. All 9.5 GHz echo-detected EPR measurements, except for the quantitative ones (Fig. 2c), were performed with an interpulse delay $\tau=128 \mathrm{~ns}$; for quantitative pulse measurements, the delay was set to $\tau=144 \mathrm{~ns}$.

\section{$\underline{35.7} \underline{\mathrm{GHz}} \underline{\text { echo-detected EPR }} \underline{\text { measurements }}$}

All 35.7 GHz echo-detected EPR spectra (Fig. S4) were recorded at a temperature of $10 \mathrm{~K}$ with a home-built Q-band spectrometer (2), using a home-built $3 \mathrm{~mm}$ Q-band resonator (3). All the spectra were recorded using a standard 2-pulse sequence $\pi / 2-\tau-\pi-\tau$ - echo; the power of microwave pulses was set up for pulse lengths $\mathrm{t}_{\pi / 2}=12 \mathrm{~ns}, \mathrm{t}_{\pi}=24 \mathrm{~ns}$ by observing the inversion of electronic magnetization in Rabi oscillations. An interpulse delay $\tau=200 \mathrm{~ns}$ was used for all 
measurements. For the home-built Q-band spectrometer, the magnetic field was corrected using Herasil (Heraeus) as a reference.

Correlation of activities and EPR signal intensities

In order to study the correlation between activities of the Ziegler-Natta catalysts and EPR signal intensities (Fig. 2a), the samples with different $\mathrm{B} / \mathrm{Ti}$ ratios $(\mathrm{B} / \mathrm{Ti}=0 ; 2.60 ; 4.10)$ were synthesized as described before. The activities towards ethylene polymerization were measured as described before to be $\left.12 \mathrm{~kg}_{P E} \cdot\left(\mathrm{g}_{\mathrm{cat}} \cdot \mathrm{h}\right)^{-1} ; 14 \mathrm{~kg}_{\mathrm{PE}} \cdot\left(\mathrm{g}_{\mathrm{cat}} \cdot \mathrm{h}\right)^{-1} ; 31 \mathrm{~kg} \mathrm{gE}_{\mathrm{P}} \cdot \mathrm{g}_{\mathrm{cat}} \cdot \mathrm{h}\right)^{-1}$, respectively. All the samples were prepared in the quartz EPR tubes with a diameter $2.93 \pm 0.04 \mathrm{~mm}$. The solid powder of the catalysts was put into the EPR tubes to fill them to the same height of $2.4 \pm 0.1 \mathrm{~cm}$ in order to fill completely the active zone of the EPR resonator. This corresponds to $43 \pm 2 \mathrm{mg}$ of the sample with $\mathrm{B} / \mathrm{Ti}=0,49 \pm 2 \mathrm{mg}$ of the sample with $\mathrm{B} / \mathrm{Ti}=2.60$ and $44 \pm 2 \mathrm{mg}$ of the sample with $\mathrm{B} / \mathrm{Ti}=4.10$. The $1 \mathrm{M}$ solution of $\mathrm{Et}_{3} \mathrm{Al}$ was added to each sample tube to the height of $3 \mathrm{~cm}$ on top of the solid powder (5.4 cm of total sample height); this grants its molar excess towards Ti (510:1).

All 9.5 GHz echo-detected EPR spectra (Fig. 2c) were measured at $10 \mathrm{~K}$ with a Bruker Elexsys E680 EPR spectrometer within one run of the spectrometer. A Bruker MS3 split-ring resonator with a length of the active zone of $1 \mathrm{~cm}$ was used for all the measurements. The sample tubes were placed in the resonator so that the bottom end of the tube was $0.8 \mathrm{~cm}$ lower than its active zone. All the measurements were performed in a similar broad microwave absorption mode of MS3 resonator with similar quality factor, which was achieved by the same height of resonator's antenna. The standard 2-pulse sequence $\pi / 2-\tau-\pi-\tau$ - echo was used for all the samples, with $\tau=$ $144 \mathrm{~ns}, \mathrm{t}_{\pi / 2}=16 \mathrm{~ns}, \mathrm{t}_{\pi}=32 \mathrm{~ns}$ (tuned at the maxima of echo intensity using Rabi oscillations). The same repetition rate of $1 \mathrm{kHz}$ was used to record all the echo-detected EPR spectra shown in Fig. 2c. We established the minimal safe repetition time for quantification by inversion recovery measurements (see Fig. S6, a). All other recording parameters, including the speed of the field sweep, the number of accumulations and the gain of the amplifiers, were the same for all the samples. We also checked that transverse relaxation times were the same within experimental uncertainty for all samples $\left(T_{2}=40 \pm 3 \mathrm{~ns}\right.$, Fig. S6, b).

In Fig. 2a, all EPR signal intensities are normalized to the signal intensity for the sample with $\mathrm{B} / \mathrm{Ti}=4.10$ by the ratio of weights of the samples. All EPR signal intensities were further normalized by the ratio of activity to intensity of the sample with $\mathrm{B} / \mathrm{Ti}=4.10$.

\section{HYSCORE spectroscopy}

9.5 GHz HYSCORE measurements were performed on a Bruker Elexsys E680 EPR spectrometer using a Bruker MS3 split-ring resonator. For the HYSCORE measurements, the standard 4-pulse sequence $\pi / 2-\tau-\pi / 2-\mathrm{t}_{1}-\pi$ - $\mathrm{t}_{2}-\pi / 2-\tau$-echo with pulse lengths $\mathrm{t}_{\pi / 2}=24 \mathrm{~ns}, \mathrm{t}_{\pi}=16 \mathrm{~ns}$ was used. Time steps $\Delta t_{1}$ and $\Delta t_{2}$ were set to $16 \mathrm{~ns}$. An eight-step phase cycle was used to remove unwanted echo contributions. The repetition rate was set to $2 \mathrm{kHz}$. The length of HYSCORE traces was set to $2160 \mathrm{~ns}$ in both dimensions. The final spectrum (Fig. 3b) was obtained via the summation of the HYSCORE spectra with $\tau=128 \mathrm{~ns}, \tau=160 \mathrm{~ns}$ and $\tau=192 \mathrm{~ns}$ to compensate for blind spots.

\section{Simulation of HYSCORE spectra}

All numerical simulations of experimental HYSCORE spectra were performed in EasySpin (1) with the saffron function, which took as an input either manually estimated parameters of ${ }^{1} \mathrm{H}$ 
hyperfine and ${ }^{27} \mathrm{Al}$ hyperfine and quadrupole couplings (Fig. 3b), or DFT computed parameters of ${ }^{1} \mathrm{H}$ hyperfine tensors (Fig. 3d \& Figs. S8 - S11). Spectra were simulated for interpulse delays $\tau=$ $128 \mathrm{~ns}, \tau=160 \mathrm{~ns}$ and $\tau=192 \mathrm{~ns}$, assuming infinite bandwidth of microwave pulses. The parameters of hyperfine couplings are described through the principal values of hyperfine tensors in the form $\mathbf{A}=\mathrm{a}_{\text {iso }}+\mathbf{a}_{\text {dip }}=\left[\mathrm{a}_{\text {iso }}+\mathrm{a}_{\mathrm{dip}}(1) ; \mathrm{a}_{\text {iso }}+\mathrm{a}_{\mathrm{dip}}(2) ; \mathrm{a}_{\text {iso }}+\mathrm{a}_{\mathrm{dip}}(3)\right]$. The $a_{\text {iso }}$ value designates the isotropic part of the hyperfine tensor, associated with Fermi contact interaction, while $\mathbf{a}_{\text {dip }}=$ $\left[\mathrm{a}_{\text {dip }}(1) ; \mathrm{a}_{\text {dip }}(2) ; \mathrm{a}_{\text {dip }}(3)\right]$ designates the anisotropic part of the hyperfine tensor, associated with dipole-dipole interactions. In manual simulation of ${ }^{1} \mathrm{H}$ hyperfine couplings, the anisotropic part was presented as $\mathbf{a}_{\text {dip }}=\left[-T_{\text {dip }} ;-T_{\text {dip }} ; 2 \cdot T_{\text {dip }}\right]$, where $T_{\text {dip }}$ is the constant of dipole-dipole interaction. This assumes strict localization of the electron spin on $\mathrm{Ti}^{3+}$ (point-dipole approximation). The $\mathrm{Ti}^{3+}{ }^{1} \mathrm{H}$ distance can then be estimated through the following formula:

$$
\mathrm{r}_{\mathrm{Ti}-\mathrm{H}}=\sqrt[3]{\frac{\gamma_{e} \gamma_{N} \mu_{0} \hbar}{8 \pi^{2} T_{\text {dip }}}}
$$

The ${ }^{27} \mathrm{Al}$ quadrupole coupling was defined through the quadrupole coupling constant $P$ and the rhombicity of quadrupole tensor $\eta$.

\section{DFT-based geometry optimizations}

All geometry optimizations, including the optimization of the main model for the active species (Fig. 3c) and all the other tested models (Fig. S8 - S10) were performed with the ORCA 3 (4) program. The unrestricted Kohn-Sham formalism with the PBE0 functional (5) was used, together with Grimme's three-center dispersion correction (6) and the COSMO (7) continuum solvation model for toluene. For all the optimizations, the RIJCOSX approximation (8) was applied, together with an auxiliary basis set (9) def2-TZVPP/J and increased numerical precision of COSX integration (IntAccX 7,7,7; GridX 7,7,7 in ORCA convention).

For all developed models, the $\mathrm{MgCl}_{2}$ surface was represented as a $\left\{\mathrm{Mg}_{8} \mathrm{Cl}_{16}\right\}$ cluster, following previous work (10). During the optimizations, the cluster coordinates were fixed, while having the first Ti(III) coordination sphere and all the other atoms fully relaxed.

\section{DFT-based calculation of EPR parameters}

All ${ }^{1} \mathrm{H}$ hyperfine and ${ }^{27} \mathrm{Al}$ hyperfine and quadrupole couplings (Fig. 3c; Fig. S8 - S11) were calculated based on previously optimized structures. The calculations were performed in ORCA 4 (11), using the unrestricted Kohn-Sham formalism with PBE0 (5) together with Grimme's threecenter dispersion correction (6). Note that the dispersion correction affects only energy, but not the DFT wavefunction and is thus immaterial for spin-Hamiltonian parameter computations at given geometry (12). The double- $\zeta$ EPR-II (13) basis set was used for $\mathrm{C}$ and $\mathrm{H}$ atoms, as it has proven its efficiency for calculations of ${ }^{1} \mathrm{H}$ hyperfine couplings for Ti(III) alkyls $(14,15)$. The ccpCVTZ (triple- $\zeta$ with core correlation) basis set (16) was used for Al atom, following the previous calculations of ${ }^{27} \mathrm{Al}$ hyperfine and quadrupole couplings in Ti(III)-Al bimetallic system (17). The triple- $\zeta$ TZVP (18) basis set was used for all other atoms. For all calculations, the CPCM solvation model (19) was used.

\section{Determination of $\underline{\pi}$ character in $\underline{\mathrm{Ti}-\mathrm{C}}$ bonds}

The degree of $\pi$ character in Ti-C bonds was estimated through the angle of deviation of the maximum amplitudes of the related natural hybrid orbitals (NHO) on $\alpha$-carbon atoms of $\left(\mathrm{CH}_{2}{ }^{\mathrm{t}} \mathrm{Bu}\right)$ ligands from the Ti-C axis. The NHO were evaluated within the natural bond orbital (NBO) 
analysis, performed in ORCA 4 (11) and GenNBO 7.0 (20) programs for the optimized structures. For the NBO analysis, the same DFT parameters as the ones used for the calculation of hyperfine and quadrupole tensors were applied.

\section{Supplementary Text}

Validation of Spectroscopic Methodology: Polymerization performances of alkylated NMR \& EPR samples

To ensure that our spectroscopic study was representative of the active centers (these "pre-active sites" become active sites in the presence of ethylene), we ran "control" polymerizations with the "activated ZN powder" without and with externally added Et $\mathrm{t}_{3} \mathrm{Al}$, and with the toluene-dispersed activated catalyst (see Table S2). Noticeably, even the raw "activated ZN powder" dispersed in heptane promoted the polymerization of ethylene without any other reagent than monomer, although with a quickly deactivating profile. The expected activity profile was then restored when dispersing the "activated $\mathrm{ZN}$ powder" in the 3 mmolar-[Et $3 \mathrm{Al}]$ heptane solution, and adding ethylene. Similarly, the EPR-representative sample promoted the polymerization of ethylene upon dispersion in heptane. This set of experiments is consistent with our spectroscopic experimental procedures allowing for a good insight in the $\mathrm{ZN}$ catalysis' active centers.

\section{Paramagnetic NMR $\underline{\text { studies }}$}

The ${ }^{11} \mathrm{~B}$ NMR spectroscopy reveals the presence of boron alkoxide species in the Bcontaining Ziegler-Natta precatalysts before $\mathrm{Et}_{3} \mathrm{Al}$ addition (Fig. S1) and the formation of $\mathrm{BEt}_{3}$ after the $\mathrm{Et}_{3} \mathrm{Al}$ addition (Fig. S2).

Paramagnetic ${ }^{1} \mathrm{H}-\mathrm{NMR}$ techniques under ultra-fast MAS conditions (21) were applied to the samples of heterogeneous Ziegler-Natta catalysts with $\mathrm{B} / \mathrm{Ti}=0$ and $\mathrm{B} / \mathrm{Ti}=1.35$, activated with $\mathrm{Et}_{3} \mathrm{Al}$. Similar ${ }^{1} \mathrm{H}$ paramagnetic species were found for both samples with and without $\mathrm{BCl}_{3}$, while being noticeably more pronounced in the spectra of the $\mathrm{BCl}_{3}$-treated samples (Fig. S3). These signals, having a paramagnetic shielding contribution, indicates the presence of Ti(III) alkyl species.

\section{$\underline{35.7} \mathrm{GHz}$ EPR studies}

The $35.7 \mathrm{GHz}$ echo-detected EPR spectra (Fig. S4, a) of Ziegler-Natta catalysts with $\mathrm{B} / \mathrm{Ti}=$ $0 ; 2.6 ; 4.2$ show an intense line at $1280-1500 \mathrm{mT}$, related to the signals around $340-390 \mathrm{mT}$ in $9.5 \mathrm{GHz} \mathrm{CW}$ EPR spectra (Fig. 2b). This line was previously assigned to several $\mathrm{TiCl}_{3}$ species, using Q-band (34 GHz) HYSCORE spectroscopy (10). In the present work, we tested for a possible contribution of Ti(III) alkyl species at these field positions, but did not detect coupled ${ }^{1} \mathrm{H}$ nuclei by Q-band HYSCORE, Q-band 3-pulse ESEEM (22) and Q-band Davies ENDOR (23) techniques.

The $35.7 \mathrm{GHz}$ echo-detected EPR spectra show also a signal around $1276 \mathrm{mT}$ (Fig. S4, a, marked with arrow) which tends to grow with an increase in the $\mathrm{B} / \mathrm{Ti}$ ratio. This $35.7 \mathrm{GHz}$ EPR signal is essentially the same signal with $g=\left[\begin{array}{ll}2.0023 & 2.0053 \\ 2.1289\end{array}\right]$, which was observed in 9.5 GHz pulse EPR spectra (Fig. 2c), as revealed by the comparison of the two spectra (Fig. S4, b). However, it is strongly suppressed in the $35.7 \mathrm{GHz}$ echo-detected EPR spectra. Hence, it appears that only the $9.5 \mathrm{GHz}$ CW EPR spectra (see Fig. 2b \& Fig. 3a) contain the complete spectral pattern of paramagnetic species in heterogeneous Ziegler-Natta catalysts, showing two types of signals with $g \geq 2.0023$ and $g<2.0023$. While the former type is observed well in $9.5 \mathrm{GHz}$ pulse EPR 
spectra, but strongly suppressed in $35.7 \mathrm{GHz}$ pulse EPR spectra, the latter type is easily observed in $35.7 \mathrm{GHz}$ echo-detected EPR spectra, but completely suppressed at $9.5 \mathrm{GHz}$.

The signal with $g=[2.00232 .00532 .1289]$ can also be recognized as a weak contribution in in Q-band echo-detected EPR spectra of boron-free Ziegler-Natta catalysts for propylene polymerization previously measured by others (10). This signal was not discussed in previous work, where it appeared to be a rather minor contribution.

\section{$\underline{9.5} \underline{\mathrm{GHz}} \underline{\mathrm{CW}} \underline{\mathrm{EPR}} \underline{\text { studies }}$}

All 9.5 GHz CW EPR spectra (Fig. 2b) were simulated assuming the presence of four distinct paramagnetic species, as described in the Materials and Methods part. While the $g$ tensor parameters for the axially symmetric species $\left(g=\left[\begin{array}{ll}2.0023 & 2.00532 .1289\end{array}\right]\right)$ were estimated from the simulation of the $9.5 \mathrm{GHz}$ echo-detected EPR spectrum (Fig. S5, a) and kept fixed for all the other simulations, the EPR parameters for the other three paramagnetic species (Fig. S5, b - d) were relaxed during the fit. Despite the fact that all the spectra were fitted separately, the best-fit $g$ tensor parameters are very similar across all samples for each of the species, with differences not exceeding line width (see Table S3). We thus evaluated the final $g$ tensor parameters as averages of the individual fits. The species with $g_{\text {average }}=\left[\begin{array}{l}1.81671 .86571 .9156\end{array}\right]$ resembles the $\mathrm{TiCl}_{3}$ species on $\mathrm{MgCl}_{2}$ (110) surface with $g=\left[\begin{array}{ll}1.84 & 1.888 \\ 1.936\end{array}\right]$, described in previous work (10), while the species with $g_{\text {average }}=\left[\begin{array}{llll}1.8910 & 1.9402 & 1.9621\end{array}\right]$ are close to previously characterized $(10) \mathrm{TiCl}_{3}$ species on $\mathrm{MgCl}_{2}$ (104) surface with $g=$ [1.89 1.945 1.96]. The third of these species with $g_{\text {average }}$ $=\left[\begin{array}{lll}1.9642 & 1.9716 & 1.9902\end{array}\right]$ was also observed in previous characterization $\left(g=\left[\begin{array}{lll}1.96 & 1.968 & 1.976\end{array}\right)\right.$. We did not detect ${ }^{1} \mathrm{H}$ couplings for any of these species. Hence, we assign all of them to various surface species of $\mathrm{TiCl}_{3}$ type.

Correlation of activities and EPR signal intensities

All 9.5 GHz echo-detected EPR spectra, shown on Fig. 2c, were measured with the same filling height of the samples in the EPR tubes (see Materials and Methods) to ensure the same filling factor between the measurements. All the spectra were measured in the same broad mode of the Bruker MS3 resonator to ensure nearly the same quality factor between the measurements. Therefore, the EPR signal intensity is expected to depend only on the quantity of paramagnetic species.

We further studied the relaxation properties of the intense axially symmetric EPR signal, observed in $9.5 \mathrm{GHz}$ pulse EPR spectra (Fig. 2c). The inversion recovery curves for all three samples with $\mathrm{B} / \mathrm{Ti}=0, \mathrm{~B} / \mathrm{Ti}=2.6$ and $\mathrm{B} / \mathrm{Ti}=4.1$ are shown on Fig. S6, a. Complete recovery of echo intensity is safely achieved in $500 \mu \mathrm{s}$ after the $\pi$ pulse. Hence, a repetition rate of $2 \mathrm{kHz}$ or lower is safe. For quantification of relative spin count, the repetition rate was lowered to $1 \mathrm{kHz}$. The transverse relaxation time $T_{2}=40 \pm 3 \mathrm{~ns}$ is the same within experimental uncertainty for all samples (Fig. S6, b). We can thus assume that echo intensity at $9.5 \mathrm{GHz}$ depends only on the quantity of this species.

Based on the correlation between the $9.5 \mathrm{GHz}$ pulse EPR signal intensity and the activity of the Ziegler-Natta catalysts (Fig. 2a), which is expected to be proportional to the number of the active sites of the catalysts, we assign the axially symmetric signal in the $9.5 \mathrm{GHz}$ echo-detected EPR spectra (Fig. 2c) to the active species of $\mathrm{MgCl}_{2}$-supported Ziegler-Natta catalysts. This signal, being observable as well in $35.7 \mathrm{GHz}$ (Q-band) pulse EPR spectra (Fig. S4), was previously detected by others in boron-free Ziegler-Natta catalysts of propylene polymerization (10). We 
detect it in all the samples (both boron-free and boron-containing) studied in the present work (see Figs. 2c \& 3a), which further supports our assignment of this signal to the spectroscopic signature of the active species.

\section{HYSCORE spectroscopy.}

The experimental 9.5 GHz HYSCORE spectrum (Fig. S7, a) contains the signals that originate from ${ }^{1} \mathrm{H}$ hyperfine and ${ }^{27} \mathrm{Al}$ hyperfine and quadrupole couplings. We do not find ${ }^{35} \mathrm{Cl}$ or ${ }^{37} \mathrm{Cl}$ signals, which might be expected in such system. Most likely, this is because of a distribution of the intensity over a broad range of frequencies due to strong quadrupole couplings. The intensity would then be below the noise level. The experimental HYSCORE spectrum was simulated using manual fitting by visual comparison of experimental and simulated HYSCORE spectral patterns (Fig. S7, b). The estimated parameters of ${ }^{1} \mathrm{H}$ hyperfine and ${ }^{27} \mathrm{Al}$ hyperfine and quadrupole couplings, together with the uncertainties of such an evaluation, are indicated below.

$$
\begin{aligned}
& \mathrm{a}_{\text {iso }}\left({ }^{1} \mathrm{H}\right)=-7.5 \pm 0.5 \mathrm{MHz} \\
& \mathrm{T}_{\text {dip }}\left({ }^{1} \mathrm{H}\right)=2.5 \pm 0.5 \mathrm{MHz} \\
& \mathbf{a}_{\text {dip }}\left({ }^{1} \mathrm{H}\right)=[-2.5 \pm 0.5 ;-2.5 \pm 0.5 ; 5.0 \pm 1.0] \mathrm{MHz} \\
& \mathrm{r}_{\mathrm{Ti}-\mathrm{H}}=3.16 \pm 0.24 \AA \\
& \mathrm{a}_{\text {iso }}\left({ }^{27} \mathrm{Al}\right)=1.5 \pm 0.2 \mathrm{MHz} \\
& \mathbf{a}_{\text {dip }}\left({ }^{27} \mathrm{Al}\right)=[-0.5 \pm 0.1 ;-0.5 \pm 0.1 ; 1.0 \pm 0.2] \mathrm{MHz} \\
& \mathrm{P}\left({ }^{27} \mathrm{Al}\right)=-42 \pm 1 \mathrm{MHz} \\
& \eta\left({ }^{27} \mathrm{Al}\right)=0.5 \pm 0.1 \mathrm{MHz}
\end{aligned}
$$

Note that the manual simulation was performed assuming that there is only one coupled ${ }^{1} \mathrm{H}$ nucleus in the system. Therefore, the indicated $\mathrm{Ti}-\mathrm{H}$ distance $\mathrm{r}_{\mathrm{Ti}-\mathrm{H}}=3.16 \pm 0.24 \AA$ is an average distance to the most strongly coupled ${ }^{1} \mathrm{H}$ nuclei.

Evaluation of the structure of the active species.

Based on comparison of the experimental 9.5 GHz HYSCORE spectrum with simulations based on DFT-computed EPR parameters, a model for the structure of the active species of $\mathrm{MgCl}_{2}$ supported Ziegler-Natta catalysts can be developed. In order to find a reasonable model, several likely structures were designed and optimized using the DFT approach. Afterwards, the parameters of ${ }^{1} \mathrm{H}$ hyperfine and ${ }^{27} \mathrm{Al}$ hyperfine and quadrupole couplings were calculated for each structure and used for simulations of HYSCORE spectra. The setup of DFT calculations for geometry optimization and calculation of EPR parameters (see Materials and Methods) is based on experience in such calculations for Ti(III) alkyl complexes $(14,15)$. Note that the ${ }^{27} \mathrm{Al}$ hyperfine couplings in Ti(III)-Al complexes may not be a reliable indicator of agreement between model and experimental data, as, with the used basis set, the magnitude of ${ }^{27} \mathrm{Al}$ hyperfine coupling was underestimated for Ti(III)-Al bimetallic complex (17). However, the ${ }^{1} \mathrm{H}$ hyperfine couplings were previously found to provide fingerprints of different conformations of Ti(III) alkyls, being rather sensitive to even small structural changes (14). Therefore, we used similarity of simulated and experimental ${ }^{1} \mathrm{H}$ HYSCORE patterns as the main criterion for evaluation of the right model ("precise criterion"). We still rejected models for which the calculated ${ }^{27} \mathrm{Al}$ hyperfine couplings $\mathrm{a}_{\text {iso }}\left({ }^{27} \mathrm{Al}\right)$ were larger by more than $1 \mathrm{MHz}$ compared to the experimental values, estimated by the manual fitting ("less precise criteria"), or where the ${ }^{27} \mathrm{Al}$ hyperfine couplings are negligibly small (see Fig. S8, c). 
Using such an approach, we were able to reject all structures where the Ti(III) center does not have directly coordinated alkyl ligands (Fig. S8, a \& b), since the calculated $a_{\text {iso }}\left({ }^{1} \mathrm{H}\right)$ values are too small in case of alkyl ligands being coordinated exclusively to an Al atom (Fig. S8, a). The same is true if the alkyl ligands are replaced by alkoxides $-\mathrm{O}\left(\mathrm{CH}_{2}\right)_{4} \mathrm{Cl}(\mathrm{Fig}$. S8, b) that could have been obtained via the ring opening of surface THF molecules (24). This indicates that reacted THF is not directly involved in the structure of the active center. Furthermore, only a very small $a_{\text {iso }}$ $\left({ }^{27} \mathrm{Al}\right)=0.0016 \mathrm{MHz}$, which is in contradiction to experimental observations, is found in computations if the $\mathrm{Al}$ atom is not connected to $\mathrm{Ti}$ (III) through only one bridging atom (Fig. S8, c). Therefore, we assign the structure of the active species of Ziegler-Natta catalysts to a bimetallic $\mathrm{Ti}-\mathrm{Al}$ complex with the organometallic ligands directly coordinated to $\mathrm{Ti}$, as it was previously proposed by Guilio Natta (25).

At first, we tested models that contain a four-coordinated $\mathrm{Al}$ atom in their structure, including the $\left(\mathrm{C}_{2} \mathrm{H}_{5}\right) \mathrm{ClTi}-\left(\mu_{2}-\mathrm{Cl}_{2}\right)-\mathrm{Al}\left(\mathrm{C}_{2} \mathrm{H}_{5}\right)_{2}$ model (Fig. S9, a) and the $\mathrm{Cl}_{2} \mathrm{Ti}-\left(\left(\mathrm{C}_{2} \mathrm{H}_{5}\right)-\mathrm{Al}\left(\mathrm{C}_{2} \mathrm{H}_{5}\right)_{2}\right.$ model, where the $\alpha-\mathrm{C}$ atom of $\left(\mathrm{C}_{2} \mathrm{H}_{5}\right)$ ligand is coordinated to both Ti and $\mathrm{Al}$ atoms (Fig. S9, b). Both the structures shown on Fig. S9, a \& Fig. S9, b did not provide sets of ${ }^{1} \mathrm{H}$ hyperfine couplings in agreement with the experimental HYSCORE spectrum and were therefore rejected. The same was true for the $\mathrm{Cl}_{2} \mathrm{Ti}-\left(\mathrm{C}_{2} \mathrm{H}_{4}\right)-\mathrm{Al}\left(\mathrm{C}_{2} \mathrm{H}_{5}\right)_{2}$ model with $\mathrm{X}_{2}$-type $\mathrm{C}_{2} \mathrm{H}_{4}$ (Fig. S10, a), where a strong Ti$\mathrm{H}$ interaction with the $\left(\mathrm{C}_{2} \mathrm{H}_{5}\right)$ ligands coordinated to $\mathrm{Al}$ atom results in too large ${ }^{1} \mathrm{H}$ hyperfine couplings that are not observed in the experimental spectrum. Therefore, we examined as well the structure with a substitution of $\mathrm{Al}\left(\mathrm{C}_{2} \mathrm{H}_{5}\right)_{2} \mathrm{Cl}$ units by $\mathrm{AlCl}_{2}\left(\mathrm{C}_{2} \mathrm{H}_{5}\right)$, namely the $\mathrm{Cl}_{2} \mathrm{Ti}-\left(\mathrm{C}_{2} \mathrm{H}_{4}\right)$ $\mathrm{AlCl}\left(\mathrm{C}_{2} \mathrm{H}_{5}\right)$ model (Fig. S10, b). For this model, the simulated ${ }^{1} \mathrm{H}$ HYSCORE pattern is reasonably close to the experimental one. However, for this species we compute ${ }^{27} \mathrm{Al}$ isotropic hyperfine coupling of $\mathrm{a}_{\text {iso }}\left({ }^{27} \mathrm{Al}\right)=-4.67 \mathrm{MHz}$, being too large in magnitude compared to the experimental value of 1.5 MHz. Note that DFT computations on our basis set level without diffuse functions typically underestimate the isotropic ${ }^{27} \mathrm{Al}$ hyperfine coupling.

Among all models considered, only the one shown in Fig. 3c and Fig. S11, a, provides a set of ${ }^{1} \mathrm{H}$ hyperfine couplings that fits the HYSCORE spectrum nearly perfectly (see Fig. 3d \& Fig. $\mathrm{S} 11, \mathrm{~b}-\mathrm{f}$ ). This model also provides ${ }^{27} \mathrm{Al}$ hyperfine and quadrupole couplings (see Table S4), which are close to the ones derived from the manual fit. For instance, the calculated dipolar part of the hyperfine tensor $\boldsymbol{a}_{\text {dip }}$ (calculated) $=[-0.36-0.490 .85] \mathrm{MHz}$ is in a nice agreement with the one derived from the manual fit, $\boldsymbol{a}_{\text {dip }}$ (experimental) $=[-0.5-0.51 .0] \mathrm{MHz}$. Likewise, the calculated quadrupole coupling constant $P$ (calculated) $=-44.71 \mathrm{MHz}$ is also close to $P$ (experimental) $=-42$ $\mathrm{MHz}$, derived from the manual fit. These observations indicate that the $\mathrm{Ti}-\mathrm{Al}$ distance and the symmetry of the coordination sphere of the nearby $\mathrm{Al}$ atom are predicted well by the model shown on Fig. $3 \mathrm{c}$ and Fig. S11, a. The calculated ${ }^{27} \mathrm{Al}$ isotropic hyperfine coupling $a_{\text {iso }}$ (calculated) $=0.31$ $\mathrm{MHz}$ is significantly smaller than $a_{\text {iso }}$ (experimental) $=1.5 \mathrm{MHz}$. However, such an underestimate is consistent with previous observations for the used basis set (17). Therefore, we conclude that this model for the active species of heterogeneous Ziegler-Natta catalysts is consistent with our experimental data.

$g$ tensor calculations.

The unexpectedly large experimental $g$ values are reminiscent to an observation by Skorobogaty et al. for the 3,10,17,24-tetrasulphonatophthalocyanin (tspc) complex of V(IV)O in a water/DMF solution after two-electron reduction of the macrocycle (26). These authors also observed shifts in the $g$ values when substituting DMF by pyridine, with $g_{\|}$still being unusually large for a V(IV)O species, and a change to $g$ values common for $\mathrm{V}(\mathrm{IV}) \mathrm{O}$ and $g_{\perp}>g_{\|}$when the 
complex was adsorbed on a Sephadex column. For V(IV)O(tspc), assignment to a $3 \mathrm{~d}^{1}$ vanadyl species is safe, since the ${ }^{57} \mathrm{~V}$ hyperfine couplings prove large spin density on vanadium and are typical for $\mathrm{V}(\mathrm{IV}) \mathrm{O}$ species, whereas $3 \mathrm{~d}^{3}$ species have different EPR properties.

We were accidentally able to reproduce the unusually high $g$ values of $3 \mathrm{~d}^{1}$ species $\mathrm{V}(\mathrm{IV}) \mathrm{O}$ (tspc) by DFT, using the BP86 functional (27) together with the def2-TZVPP (28) basis set for all atoms and the CPCM (19) solvation model for water; the computations were performed in ORCA 4 with KDIIS and the switching to the second-order SCF (SOSCF) convergence procedure (29). The principal values of the calculated $g$ tensor for V(IV)O(tspc) of $g=[2.0081$ 2.00942 .1316 ] appeared surprisingly close to the experimental $g$ values for the active species of Ziegler-Natta heterogeneous catalysts. However, even for $\mathrm{V}(\mathrm{IV}) \mathrm{O}(\mathrm{tspc})$, where these unusually high $g$ values are experimentally observed, we were not able to reproduce them with the PBE0 (5) and TPSSh (30) functionals, where we obtained $g=\left[\begin{array}{ll}1.9573 & 1.9720 \\ 2.0065\end{array}\right]$ and $g=\left[\begin{array}{ll}1.9781 & 1.9891\end{array}\right.$ 1.9899], respectively. In fact, a computation with DIIS and without the SOSCF convergence procedure even revealed a lower-lying minimum for the BP86 function that corresponded to $g$ values lower than 2, as they are not observed for this species. Given this large variability among DFT results for the $g$ tensor, we do not consider these computations as reliable for this type of electronic structure.

The $\pi$ character of the Ti-C bond.

The structure, shown in Fig. 3c, is notable for a weak $\pi$ character in the Ti-C bond, which is evidenced by the calculated deviation of the natural hybrid orbital (NHO) on carbon from the $\mathrm{Ti}-$ $\mathrm{C}$ axis (31). For this structure such a deviation is equal to $\Theta_{\mathrm{NHO}-\mathrm{C}-\mathrm{Ti}}=9.0^{\circ}$. This makes the proposed structure similar to previously described $\beta$-diiminato Ti(III) alkyls, which are active towards ethylene polymerization going via a so-called "augmented" Cossee-Arlman mechanism (14). Such a mechanism involves a combination of the $\pi$ character in metal-carbon bonds and the delocalization of the unpaired electron, which together favor the ethylene insertion into the metalcarbon bond. Both these factors are present in the evaluated structure (Fig. 3c \& Fig. S11, a), which makes it a potentially highly active catalyst of ethylene polymerization. This further supports our assignment of the structure, shown on Fig. $3 \mathrm{c}$, to the active center of $\mathrm{MgCl}_{2}$-supported ZieglerNatta catalysts. 
a)
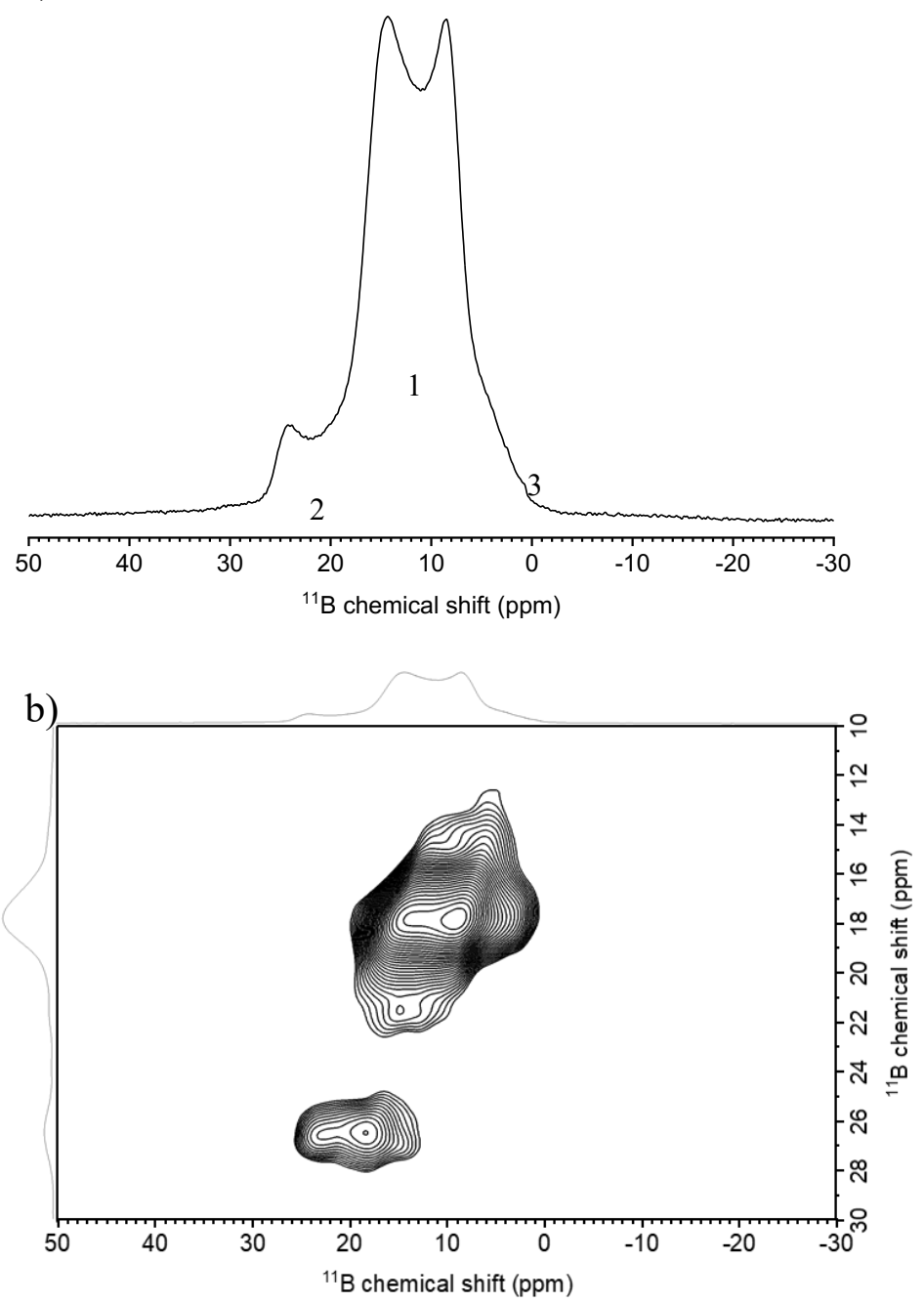

\section{Figure S1}

Solid-state ${ }^{11} \mathrm{~B}$ NMR spectroscopy study of heterogeneous Ziegler-Natta catalyst $(\mathrm{B} / \mathrm{Ti}=1.35)$ before $\mathrm{Et}_{3} \mathrm{Al}$ addition. ${ }^{11} \mathrm{~B}$ NMR spectra (a) and the result of $2 \mathrm{D}$ MQMAS ${ }^{11} \mathrm{~B}-{ }^{11} \mathrm{~B}$ (b) showing that ${ }^{11} \mathrm{~B}$ species are between $14 \mathrm{ppm}$ and $28 \mathrm{ppm}$, typical chemical shifts of boron-alkoxydes. 


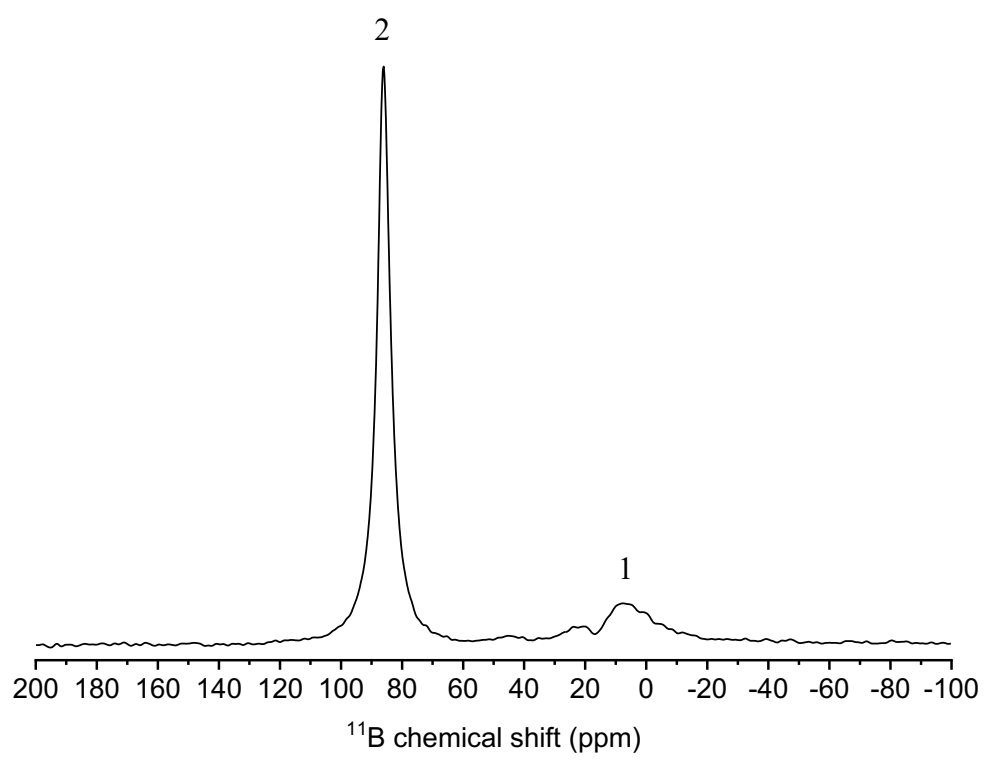

\section{Figure S2}

Solid-state ${ }^{11} \mathrm{~B}$ MAS NMR spectrum of heterogeneous Ziegler-Natta catalyst $(\mathrm{B} / \mathrm{Ti}=1.35)$ after $\mathrm{Et}_{3} \mathrm{Al}$ addition. Signals "1" correspond to boron alkoxides as it is showed in Fig. S2, a. Signal "2" at $85 \mathrm{ppm}$ correspond to chemical shift of triethylboron. Narrow and symmetric line shape of signal " 2 " without quadrupolar broadening indicates that triethylboron is present in liquid state with allowed free-rotation. 
a)

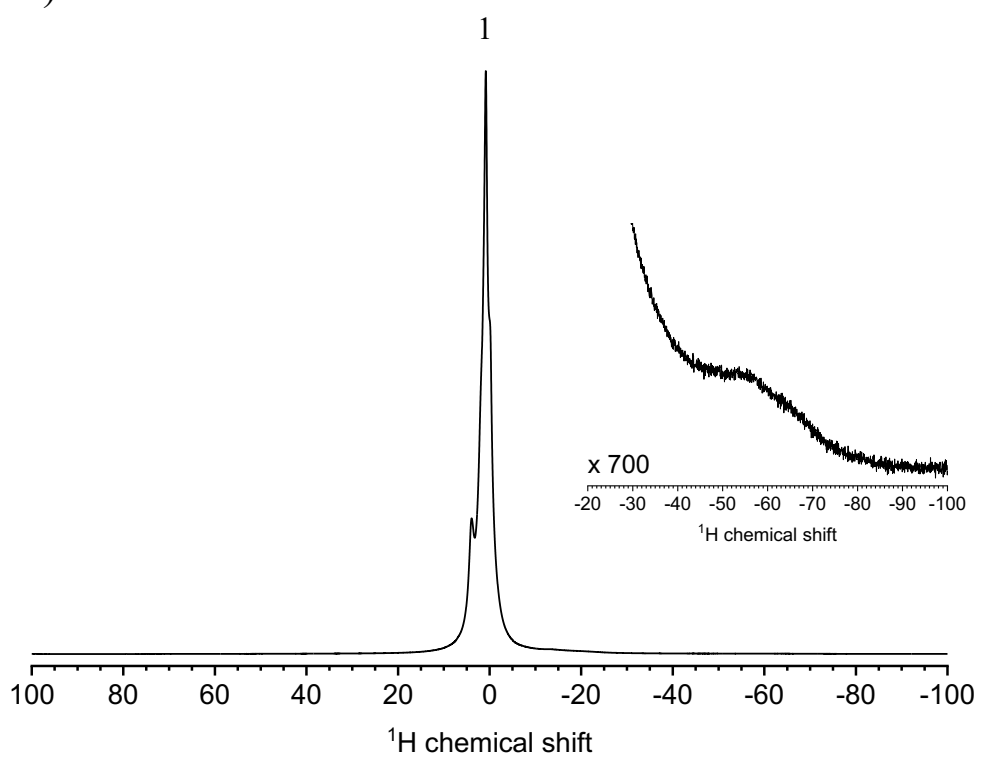

b)

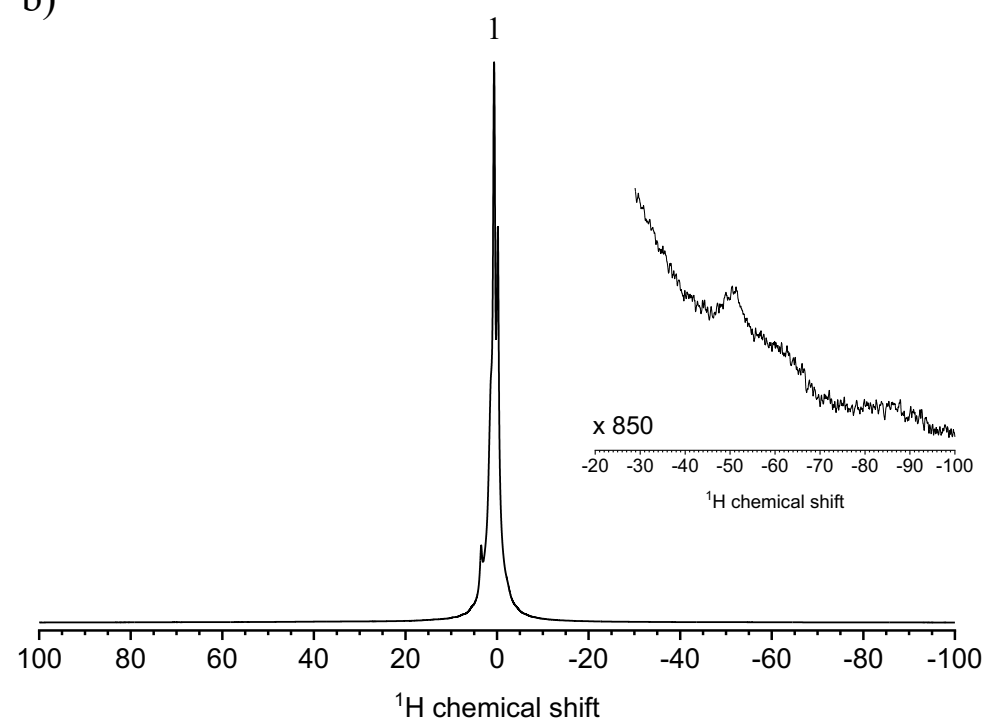

Figure S3.

Paramagnetic ${ }^{1} \mathrm{H}$ NMR spectrum of heterogeneous Ziegler-Natta catalysts in the presence of Et $\mathrm{t}_{3} \mathrm{Al}$ $(\mathrm{Al} / \mathrm{Ti}=10)$ with a magnification in the $-20 /-100 \mathrm{ppm}$ region on the paramagnetic contribution. a) $\mathrm{B} / \mathrm{Ti}=0 ; \mathrm{b}) \mathrm{B} / \mathrm{Ti}=1.35$. Signals " 1 " correspond to the diamagnetic contribution in both spectra. 
a)

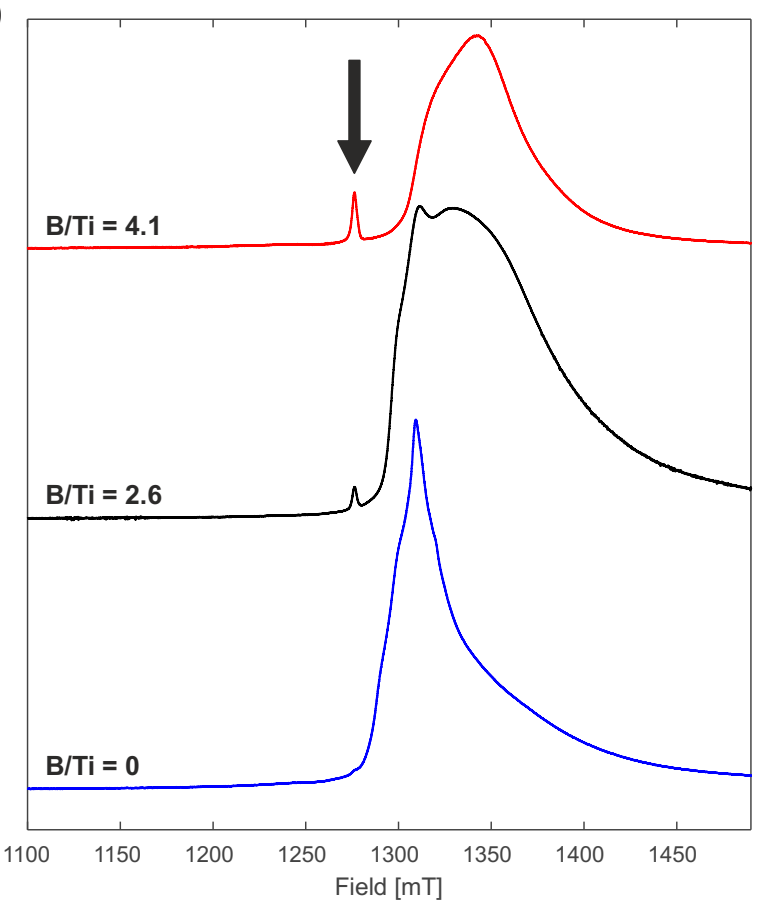

b)

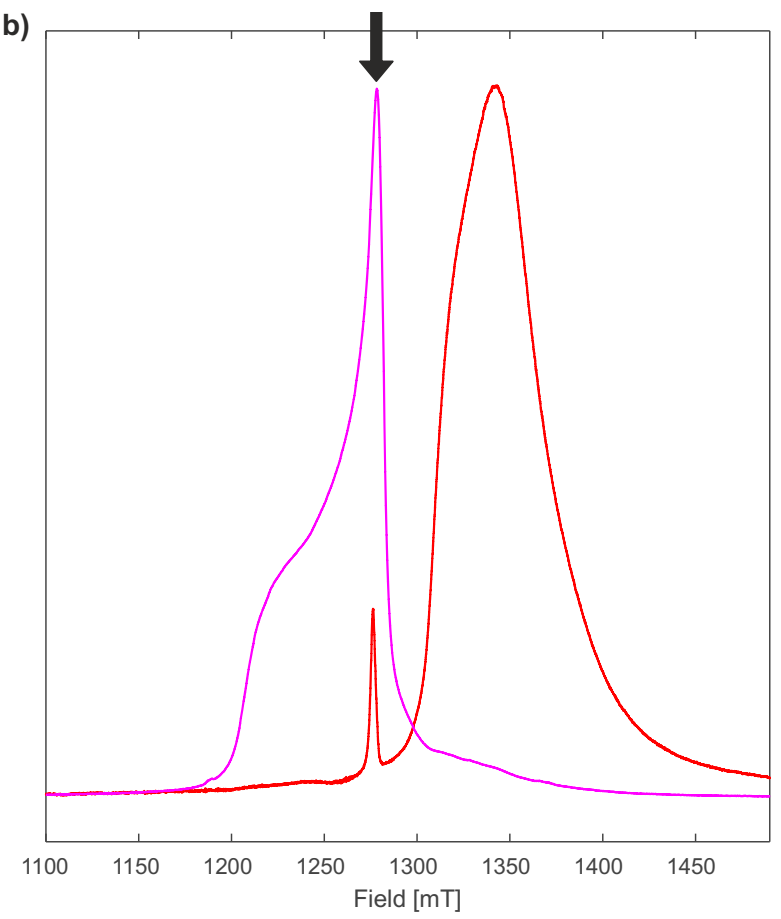

Figure S4.

a) $35.7 \mathrm{GHz}$ echo-detected EPR spectra of Ziegler-Natta catalysts with $\mathrm{B} / \mathrm{Ti}=0$ (blue), B/Ti = 2.60 (black) and $\mathrm{B} / \mathrm{Ti}=4.10$ (red). b) $35.7 \mathrm{GHz}$ (red) and $9.5 \mathrm{GHz}$ (purple) echo-detected EPR spectra of Ziegler-Natta catalyst with $\mathrm{B} / \mathrm{Ti}=4.1$. Field values for both spectra are corrected by their microwave frequencies ratio, taking into account also corrections of field offsets for both the Q-band homebuilt spectrometer and Bruker Elexsys E680 spectrometer. Intensities of the $9.5 \mathrm{GHz}$ and $35.7 \mathrm{GHz}$ spectra are equally scaled. The active species of heterogeneous Ziegler-Natta catalysts are indicated with arrows. 

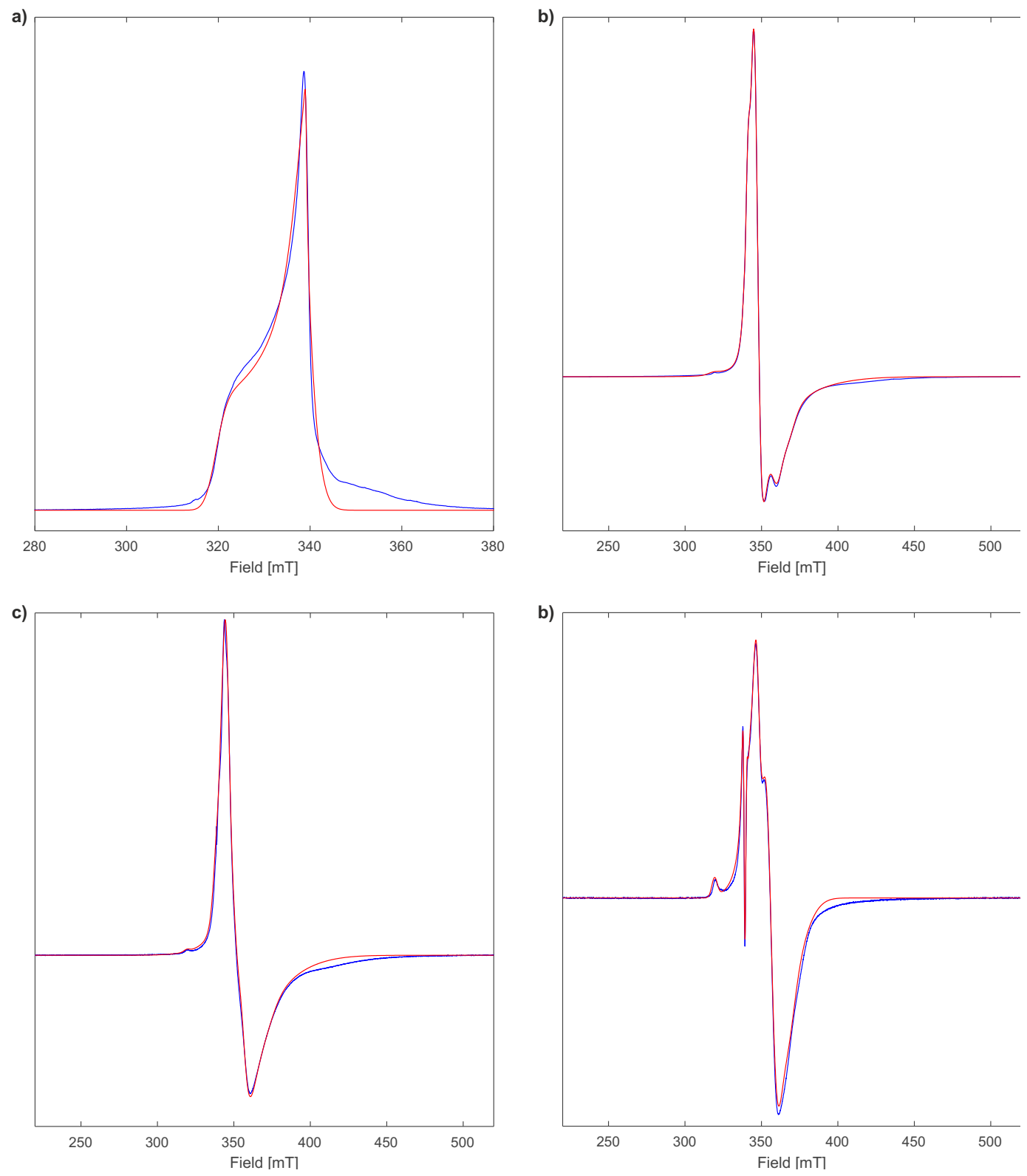

Figure S5.

Experimental spectra (blue) and their simulations (red) of the $9.5 \mathrm{GHz}$ echo-detected EPR spectrum of Ziegler-Natta catalyst with $\mathrm{B} / \mathrm{Ti}=4.10$ (a), $9.5 \mathrm{GHz} \mathrm{CW}$ EPR spectrum of ZieglerNatta catalyst with $\mathrm{B} / \mathrm{Ti}=0$ (b), $9.5 \mathrm{GHz} \mathrm{CW}$ EPR spectrum of Ziegler-Natta catalyst with $\mathrm{B} / \mathrm{Ti}=$ 2.60 (c), and $9.5 \mathrm{GHz} \mathrm{CW}$ EPR spectrum of Ziegler-Natta catalyst with B/Ti $=4.10$ (d). The $g$ tensor parameters of all the species present in CW EPR spectra are summarized in Table S3. 

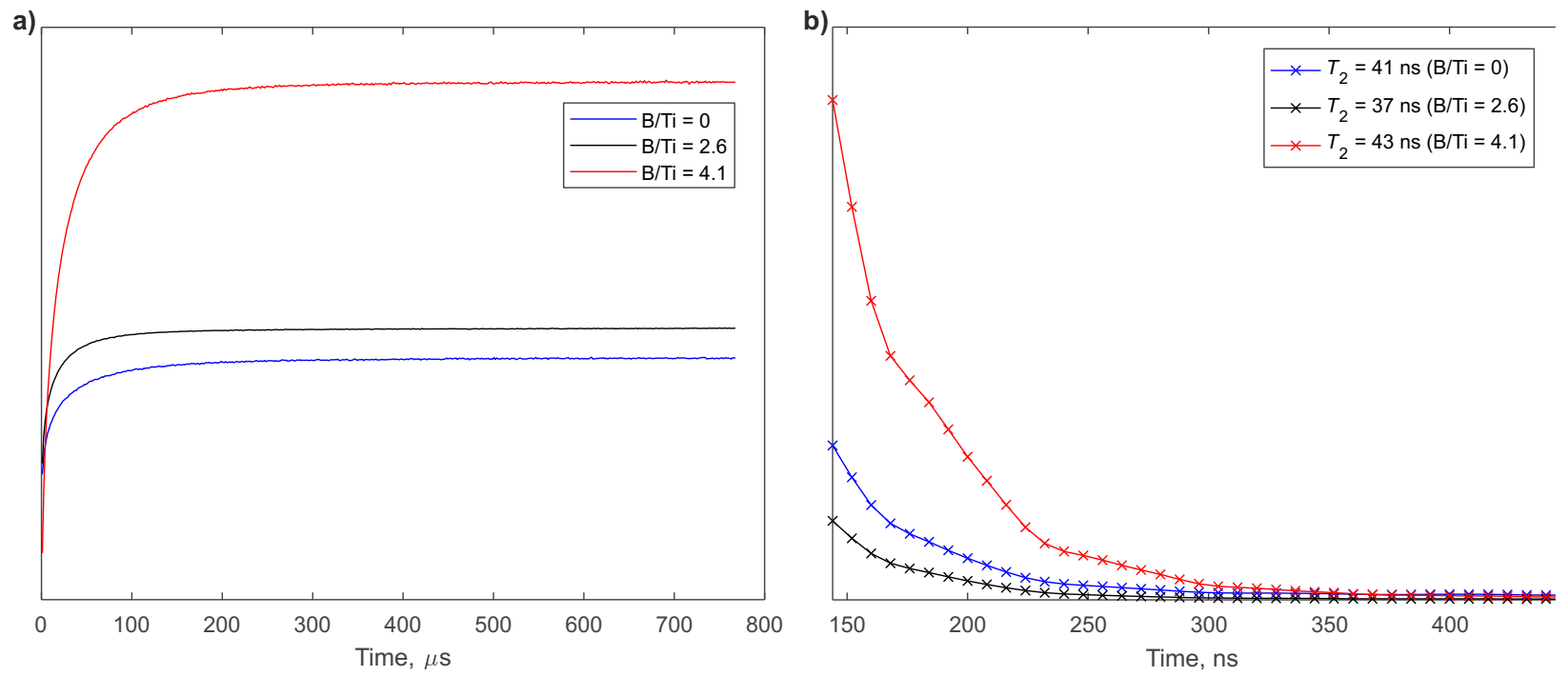

Figure S6.

a) EPR inversion recovery measurements for the samples of Ziegler-Natta catalysts with $\mathrm{B} / \mathrm{Ti}=0$ (blue), $\mathrm{B} / \mathrm{Ti}=2.6$ (black) and $\mathrm{B} / \mathrm{Ti}=4.1$ (red). b) EPR Hahn echo decay measurements for the samples of Ziegler-Natta catalysts with $\mathrm{B} / \mathrm{Ti}=0$ (blue), $\mathrm{B} / \mathrm{Ti}=2.6$ (black) and $\mathrm{B} / \mathrm{Ti}=4.1$ (red). $T_{2}$ relaxation times were determined via monoexponential fitting of Hahn echo decay curves. 

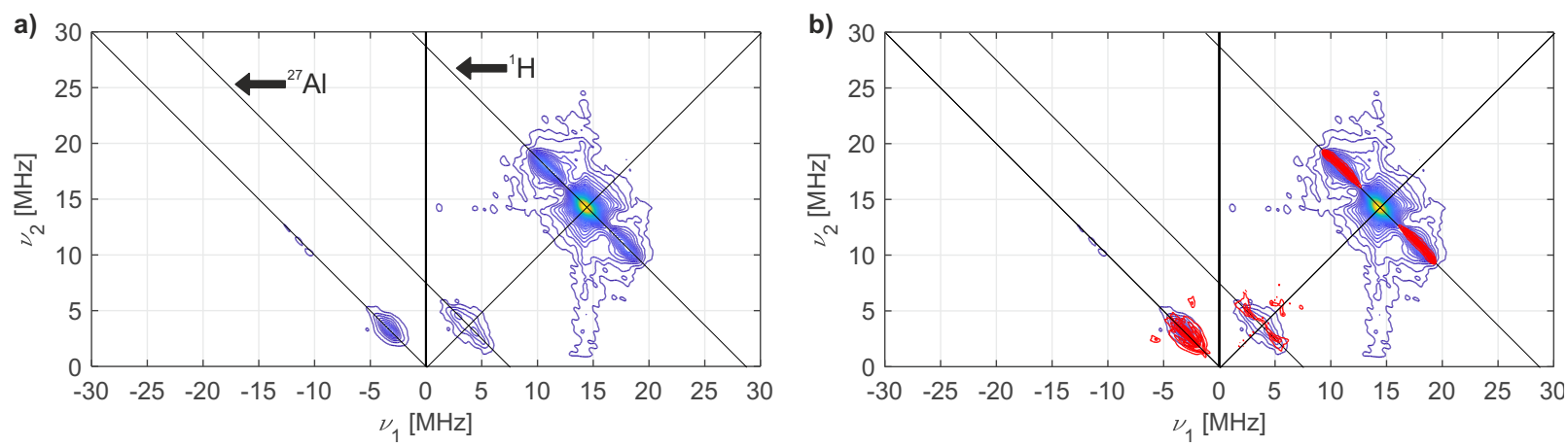

\section{Figure S7.}

a) Experimental $9.5 \mathrm{GHz}$ HYSCORE spectrum of the active species of Ziegler-Natta heterogeneous catalysts, measured for the sample with $\mathrm{B} / \mathrm{Ti}=3$. b) Simulation of the experimental HYSCORE spectrum (red). The simulation parameters are indicated in SM HYSCORE spectroscopy. 

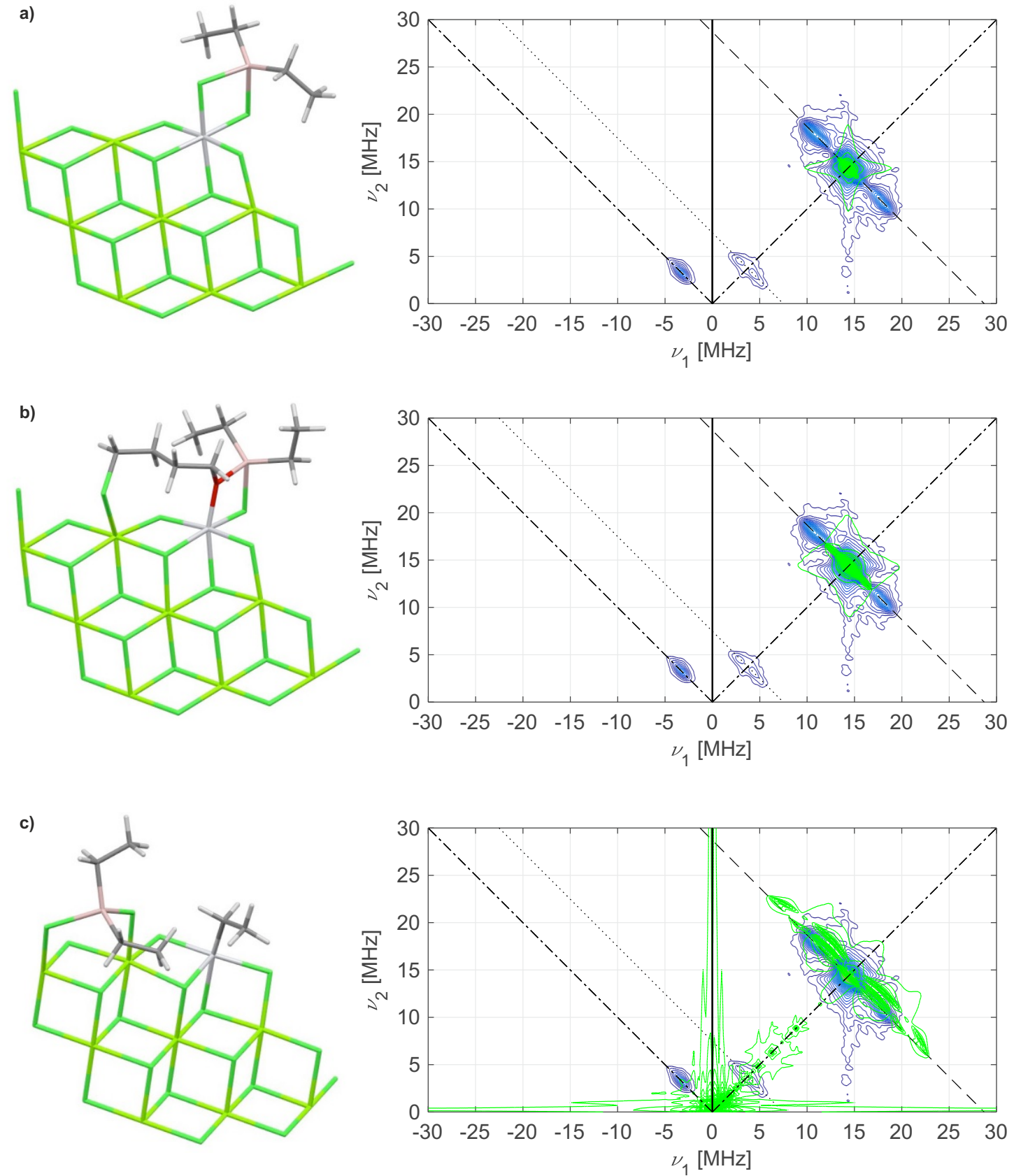

Figure S8.

a) $\mathrm{Cl}_{2} \mathrm{Ti}\left(\mu_{2}-\mathrm{Cl}_{2}\right) \mathrm{Al}\left(\mathrm{C}_{2} \mathrm{H}_{5}\right)_{2}$ model (left) and the simulation of ${ }^{1} \mathrm{H}$ HYSCORE pattern, based on the calculated ${ }^{1} \mathrm{H}$ hyperfine couplings for all $\mathrm{H}$ atoms of $\left(\mathrm{C}_{2} \mathrm{H}_{5}\right)$ ligands of the $\mathrm{Al}$ atom (right). b) $\mathrm{Cl}_{2} \mathrm{Ti}\left(\mathrm{O}\left(\mathrm{CH}_{2}\right)_{4} \mathrm{Cl}\right)\left(\mu_{2}-\mathrm{Cl}\right) \mathrm{Al}\left(\mathrm{C}_{2} \mathrm{H}_{5}\right)_{2}$ model (left) and the simulation of ${ }^{1} \mathrm{H}$ HYSCORE pattern, based on the calculated ${ }^{1} \mathrm{H}$ hyperfine couplings for all $\mathrm{H}$ atoms of the $\left(\mathrm{O}\left(\mathrm{CH}_{2}\right)_{4} \mathrm{Cl}\right)$ ligand (right). c) $\mathrm{Cl}_{2} \mathrm{Ti}\left(\mathrm{C}_{2} \mathrm{H}_{5}\right) \cdots \mathrm{AlCl}\left(\mathrm{C}_{2} \mathrm{H}_{5}\right)_{2}$ model (left) and the simulation of ${ }^{1} \mathrm{H}$ and ${ }^{27} \mathrm{Al}$ HYSCORE pattern, based on the calculated ${ }^{1} \mathrm{H}$ hyperfine and ${ }^{27} \mathrm{Al}$ hyperfine and quadrupole couplings (right). 

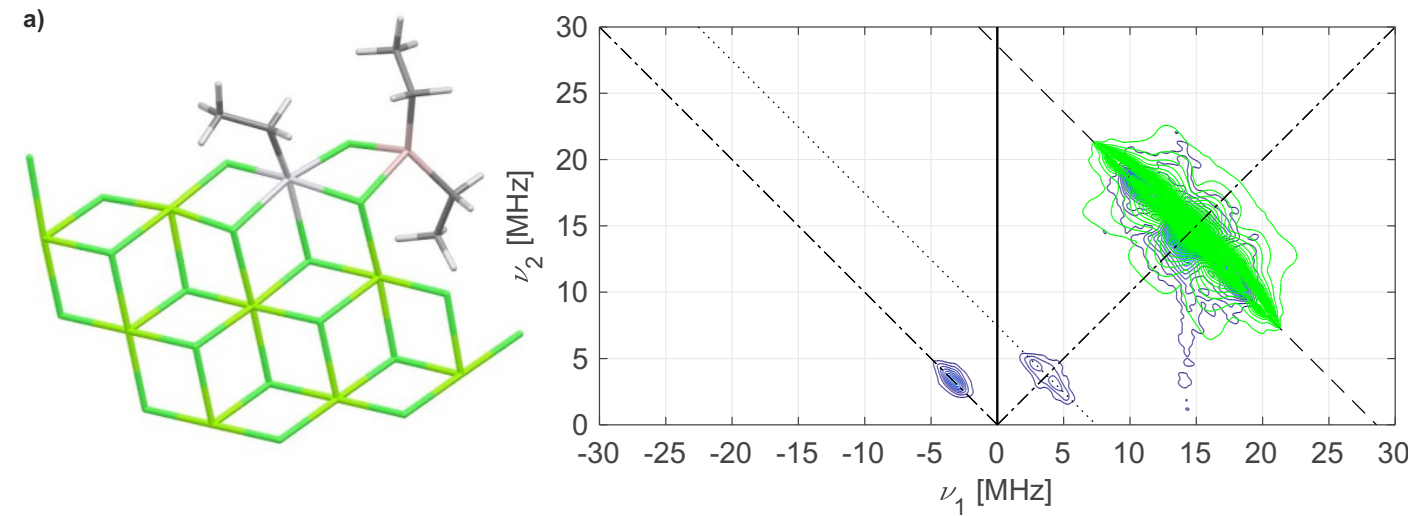

b)
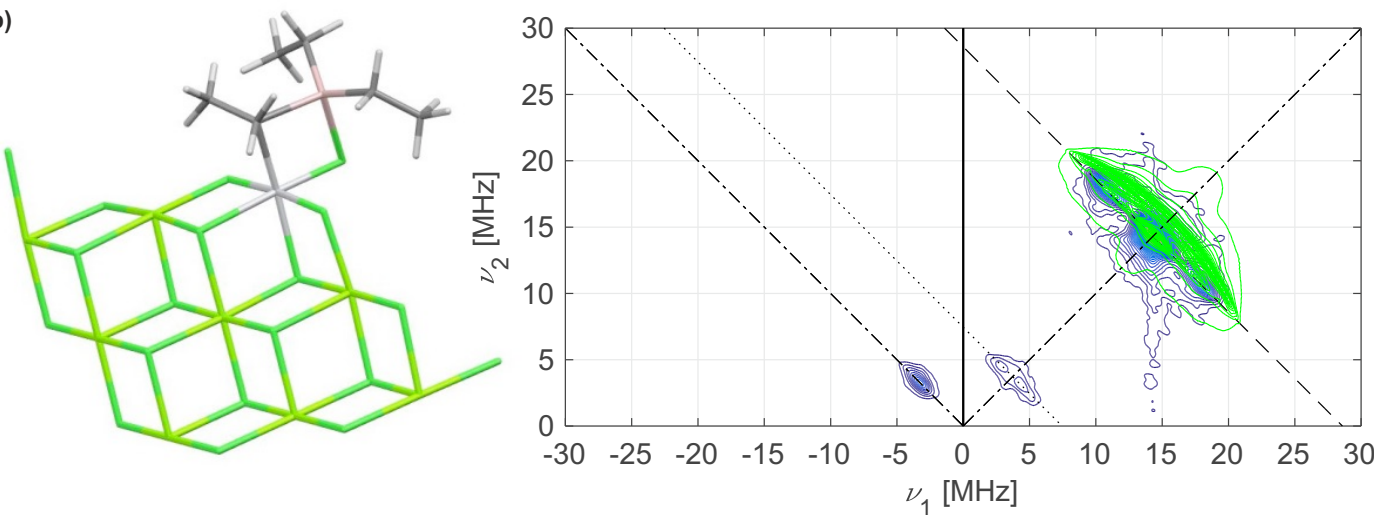

Figure S9.

a) $\mathrm{Cl}_{2} \mathrm{Ti}\left(\mathrm{C}_{2} \mathrm{H}_{5}\right)-\left(\mu_{2}-\mathrm{Cl}_{2}\right)-\mathrm{Al}\left(\mathrm{C}_{2} \mathrm{H}_{5}\right)_{2}$ model (left) and simulation of the ${ }^{1} \mathrm{H}$ HYSCORE pattern, based on the calculated ${ }^{1} \mathrm{H}$ hyperfine couplings for all $\mathrm{H}$ atoms of the $\left(\mathrm{C}_{2} \mathrm{H}_{5}\right)$ ligand on the Ti atom (right). b) $\mathrm{Cl}_{2} \mathrm{Ti}\left(\mathrm{C}_{2} \mathrm{H}_{5}\right)-\left(\mu_{2}-\mathrm{Cl}\right)-\mathrm{Al}\left(\mathrm{C}_{2} \mathrm{H}_{5}\right)_{2}$ model with a partial coordination of the $\left(\mathrm{C}_{2} \mathrm{H}_{5}\right)$ ligand to the $\mathrm{Al}$ atom (left) and simulation of ${ }^{1} \mathrm{H}$ HYSCORE pattern, based on the calculated ${ }^{1} \mathrm{H}$ hyperfine couplings for all $\mathrm{H}$ atoms of the $\left(\mathrm{C}_{2} \mathrm{H}_{5}\right)$ ligand (right). 

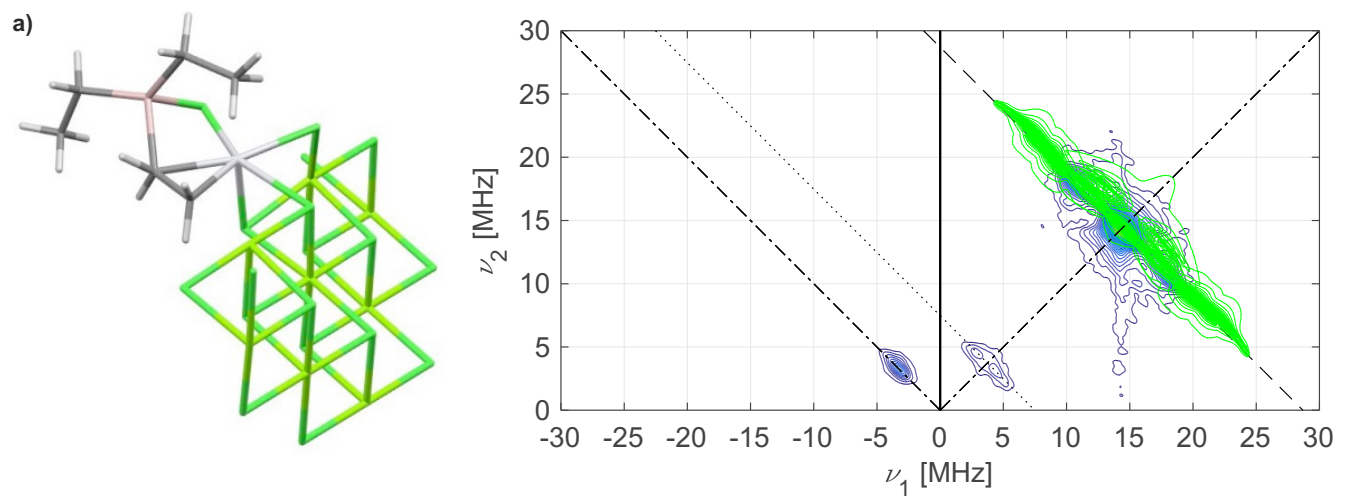

b)
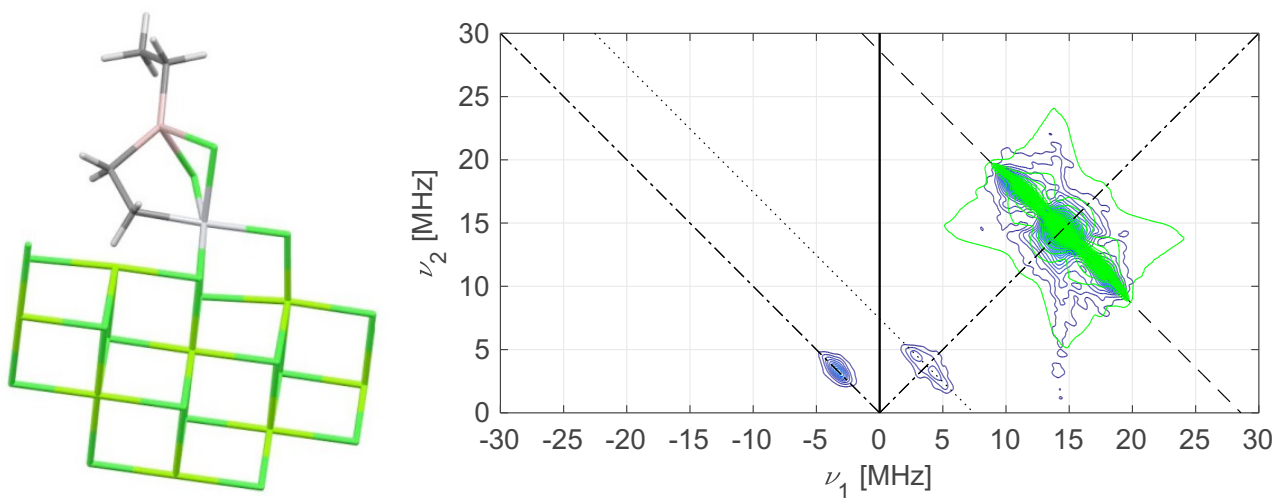

Figure S10.

a) $\mathrm{Cl}_{2} \mathrm{Ti}-\left(\mathrm{C}_{2} \mathrm{H}_{4}\right)-\mathrm{Al}\left(\mathrm{C}_{2} \mathrm{H}_{5}\right)_{2}$ model (left) and simulation of the ${ }^{1} \mathrm{H}$ HYSCORE pattern, based on the calculated ${ }^{1} \mathrm{H}$ hyperfine couplings for all $\mathrm{H}$ atoms of the $\left(\mathrm{C}_{2} \mathrm{H}_{4}\right)$ ligand and the $\left(\mathrm{C}_{2} \mathrm{H}_{5}\right)$ ligand on the $\mathrm{Al}$ atom, which interacts as well with $\mathrm{Ti}$ atom (right). b) $\mathrm{Cl}_{2} \mathrm{Ti}-\left(\mathrm{C}_{2} \mathrm{H}_{4}\right)-\mathrm{AlCl}\left(\mathrm{C}_{2} \mathrm{H}_{5}\right)$ model (left) and simulation of the ${ }^{1} \mathrm{H}$ HYSCORE pattern, based on the calculated ${ }^{1} \mathrm{H}$ hyperfine couplings for all $\mathrm{H}$ atoms of the $\left(\mathrm{C}_{2} \mathrm{H}_{4}\right)$ ligand (right). 
a)

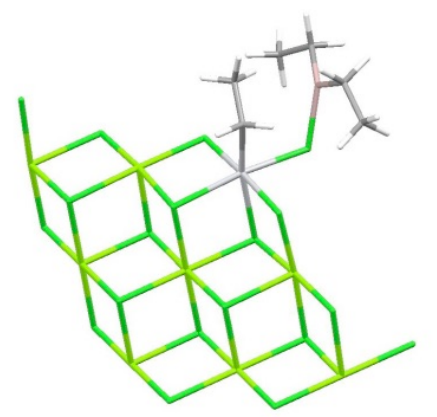

c)

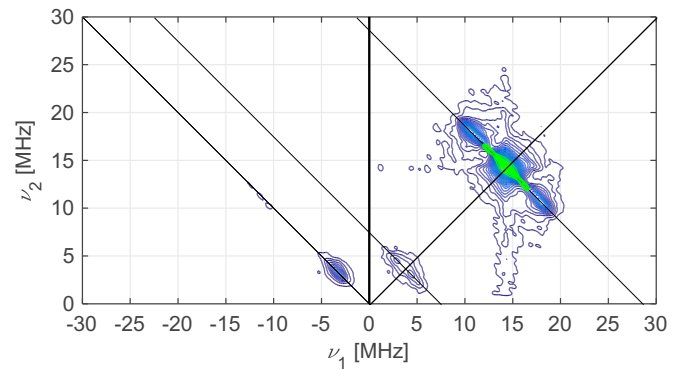

e)

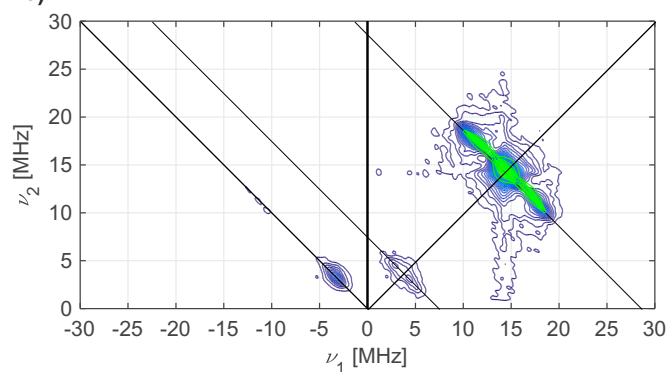

b)

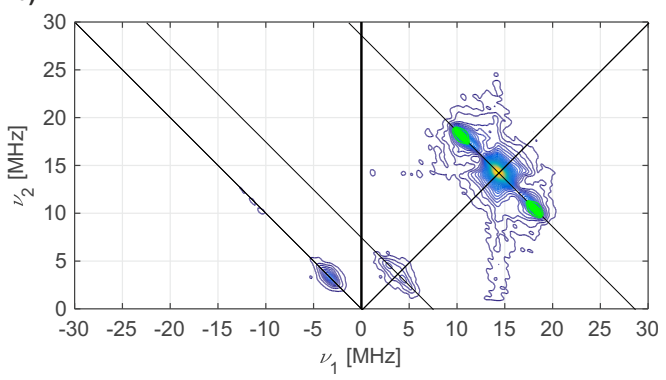

d)
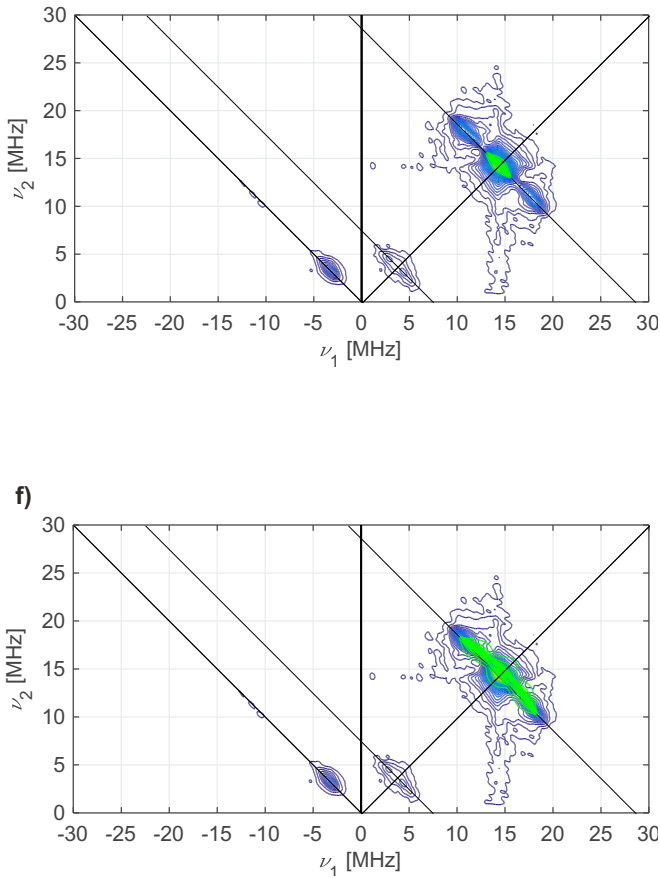

Figure S11.

a) Proposed structure of the active center of heterogeneous Ziegler-Natta catalysts. b) - d) Simulations of the ${ }^{1} \mathrm{H}$ HYSCORE pattern, based on the calculated ${ }^{1} \mathrm{H}$ hyperfine couplings for the three $\beta-\mathrm{H}$ atoms of the $\left(\mathrm{C}_{2} \mathrm{H}_{5}\right)$ ligand of the Ti atom of the proposed structure of the active center. e) - f) Simulations of the ${ }^{1} \mathrm{H}$ HYSCORE pattern, based on the calculated ${ }^{1} \mathrm{H}$ hyperfine couplings for the two $\alpha-\mathrm{H}$ atoms of the $\left(\mathrm{C}_{2} \mathrm{H}_{5}\right)$ ligand of the Ti atom of the proposed structure of the active center. 


\section{Table S1.}

Elemental analysis of all prepared samples of heterogeneous Ziegler-Natta catalysts, together with their activities towards ethylene polymerization and the molar masses of produced polyethylene.

\begin{tabular}{|c|c|c|c|c|c|c|c|}
\hline & $\begin{array}{c}\text { B/Ti ratio } \\
\text { (molar) }\end{array}$ & $\begin{array}{c}\text { \%wt. } \\
\text { B }\end{array}$ & $\begin{array}{l}\text { \%wt. } \\
\text { Ti }\end{array}$ & $\begin{array}{c}\text { Activity, } \\
\operatorname{kg}_{P E} \cdot\left(\text { gcat }_{\text {ch }}\right)^{-1}\end{array}$ & $\begin{array}{c}\text { Activity, } \\
\operatorname{kg}_{\mathrm{PE}} \cdot\left(\text { mol }_{\mathrm{Ti}} \cdot \mathbf{h}\right)^{-1}\end{array}$ & $\begin{array}{c}{ }^{*} M_{w}, \\
\text { kgmol }^{-1}\end{array}$ & ${ }^{*} \boldsymbol{\theta}=M_{w} / M_{n}$ \\
\hline 1 & 0 & 0 & 4.48 & 12 & 13000 & 220 & 3.8 \\
\hline 2 & 1.35 & 1.1 & 3.7 & 35 & 45000 & 219 & 3.5 \\
\hline 3 & 2.60 & 1.12 & 1.9 & 14 & 35000 & 231 & 3.4 \\
\hline 4 & 3.00 & 1.54 & $2.27^{* *}$ & 38 & 80000 & 178 & 3.0 \\
\hline 5 & 4.10 & 1.66 & 1.81 & 31 & 82000 & 234 & 2.9 \\
\hline
\end{tabular}

* Molar masses and Dispersities are determined by SEC-HT using universal calibration (see Materials and Methods, SEC).

** Since the [Ti] content of the sample of $B / T i=3.00$ was slightly higher than that of $B / T i=4.10$, it explains that it displayed the highest activity by weight of all tested catalysts and thus the highest corresponding characteristic signal intensity in EPR spectroscopy. 
Table S2-a.

Activity tests in polyethylene synthesis of alkylated NMR samples

\begin{tabular}{|c|c|c|c|c|c|}
\hline Catalyst & $\begin{array}{c}\text { Catalyst } \\
\text { Powder } \\
\text { Mass }\end{array}$ & $\begin{array}{c}\text { Cocatalyst } \\
\text { (overall } \\
\text { Al/Ti) }\end{array}$ & Feed & $\begin{array}{c}\text { Activity, } \\
\operatorname{kg}_{P E} \cdot\left(g_{\text {cat }} \cdot h\right)^{-1}\end{array}$ & $\begin{array}{c}\text { Activity, } \\
\operatorname{kg}_{\mathrm{PE}}\left(\mathbf{m o l}_{\mathrm{Ti}} \cdot \mathbf{h}\right)^{-1}\end{array}$ \\
\hline 1 & $5 \mathrm{mg}$ & $\begin{array}{l}\text { Standard } \\
\text { Polym. } \\
\text { Conditions } \\
(300)\end{array}$ & $\begin{array}{c}1 \mathrm{bar}_{2} / 6 \text { bar } \\
\text { ethylene }\end{array}$ & 8 & 9000 \\
\hline 1 & $5 \mathrm{mg}$ & $\begin{array}{c}\text { None } \\
\text { added (10) }\end{array}$ & $\begin{array}{c}1 \mathrm{bar}_{2} / 6 \text { bar } \\
\text { ethylene }\end{array}$ & $10(1 \mathrm{~min})^{*}$ & $11000(1 \mathrm{~min})^{*}$ \\
\hline
\end{tabular}

* Calculated over 1 min, instead of over the period of time necessary to achieve a 5-bar consumption of ethylene from the $2 \mathrm{~L}$ ballast that feeds the reactor, corresponding to about $30 \mathrm{~g}$ of polyethylene, which we consistently verified gravimetrically (see Materials and Methods, Synthesis of Polyethylenes \& Validation of Spectroscopic Methodology). In this experiment, realized with leftovers from an NMR sample preparation ( $\sim 5 \mathrm{mg})$ without any external Et ${ }_{3} \mathrm{Al}$ added, a quick deactivation was observed, due to incomplete scavenging of the polymerization medium.

Table S2-b.

Activity tests in polyethylene synthesis of alkylated EPR samples

\begin{tabular}{|c|c|c|c|c|c|}
\hline Catalyst & $\begin{array}{c}\text { Catalyst } \\
\text { Powder } \\
\text { Mass }\end{array}$ & $\begin{array}{c}\text { Cocatalyst } \\
\text { (overall } \\
\text { Al/Ti) }\end{array}$ & Feed & $\begin{array}{c}\text { Activity, } \\
\operatorname{kg}_{\mathrm{PE}} \cdot\left(\mathrm{g}_{\text {cat }} \cdot \mathbf{h}\right)^{-1}\end{array}$ & $\begin{array}{c}\text { Activity, } \\
\operatorname{kg}_{\mathrm{PE}} \cdot\left(\mathbf{m o l}_{\mathrm{Ti}} \cdot \mathbf{h}\right)^{-1}\end{array}$ \\
\hline 1 & $10 \mathrm{mg}$ & $\begin{array}{l}\text { Standard } \\
\text { Polym. } \\
\text { Conditions } \\
(300)\end{array}$ & $\begin{array}{c}1 \mathrm{bar} \mathrm{H}_{2} / 6 \text { bar } \\
\text { ethylene }\end{array}$ & 5 & 5000 \\
\hline 5 & $5 \mathrm{mg}$ & $\begin{array}{l}\text { Standard } \\
\text { Polym. } \\
\text { Conditions } \\
(300)\end{array}$ & $\begin{array}{c}1 \text { bar } \mathrm{H}_{2} / 6 \text { bar } \\
\text { ethylene }\end{array}$ & 7 & 15000 \\
\hline 5 & $25 \mathrm{mg}^{*}$ & $\begin{array}{c}\text { None } \\
\text { added (7) }\end{array}$ & $\begin{array}{c}1{\text { bar } \mathrm{H}_{2} / 6 \text { bar }} \\
\text { ethylene }\end{array}$ & 14 & 39000 \\
\hline 5 & $25 \mathrm{mg}^{*}$ & $\begin{array}{c}\text { None } \\
\text { added (7) }\end{array}$ & 7 bar ethylene & 35 & 93000 \\
\hline
\end{tabular}

* Only $25 \mathrm{mg}$ were used from a typical >40-mg EPR sample to avoid extreme exotherms in our $1 L$ reactor with our typical procedure. No fast-deactivation profile was observed, probably due to the increased mass, representative of EPR samples (see Materials and Methods, Synthesis of Polyethylenes \& Validation of Spectroscopic Methodology). When no $\mathrm{H}_{2}$ was used in combination with ethylene (to control molar masses), an even higher activity was monitored as previously observed (32). 
Table S3.

Parameters of the simulation of experimental CW EPR spectra of heterogeneous Ziegler-Natta catalysts. The error bars indicated for $g$ tensor parameters are the FWHM Gaussian parameters of inhomogeneous line broadening.

\begin{tabular}{|c|c|c|c|}
\hline Species & $\mathbf{B} / \mathbf{T i}=\mathbf{0}$ & $\mathbf{B} / \mathbf{T i}=\mathbf{2 . 6}$ & $\mathbf{B} / \mathbf{T i}=\mathbf{4 . 1}$ \\
\hline \multirow{2}{*}{ Active } & $g=[2.0023 \pm 0.0189 ;$ & $g=[2.0023 \pm 0.0189 ;$ & $g=[2.0023 \pm 0.0189 ;$ \\
species & $2.0053 \pm 0.0074 ;$ & $2.0053 \pm 0.0074 ;$ & $2.0053 \pm 0.0074 ;$ \\
& $2.1289 \pm 0.0281]$ & $2.1289 \pm 0.0281]$ & $2.1289 \pm 0.0281]$ \\
& weighting factor $1.29 \%$ & weighting factor $0.43 \%$ & weighting factor $2.01 \%$ \\
\hline \multirow{2}{*}{$\operatorname{TiCl}_{3}(1)$} & $g=[1.8085 \pm 0.3245 ;$ & $g=[1.8205 \pm 0.3045 ;$ & $g=[1.8212 \pm 0.1090 ;$ \\
& $1.8673 \pm 0.0488 ;$ & $1.8671 \pm 0.0800 ;$ & $1.8626 \pm 0.0514 ;$ \\
& $1.9142 \pm 0.0722]$ & $1.9116 \pm 0.0318]$ & $1.9209 \pm 0.0340]$ \\
& weighting factor 54.01\% & weighting factor $68.17 \%$ & weighting factor $35.74 \%$ \\
\hline \multirow{2}{*}{$\mathrm{TiCl}_{3}(2)$} & $g=[1.8902 \pm 0.0460 ;$ & $g=[1.8894 \pm 0.0601 ;$ & $g=[1.8935 \pm 0.0390 ;$ \\
& $1.9503 \pm 0.0445 ;$ & $1.9349 \pm 0.0362 ;$ & $1.9353 \pm 0.1423 ;$ \\
& $1.9613 \pm 0.0230]$ & $1.9681 \pm 0.0267]$ & $1.9570 \pm 0.0243]$ \\
& weighting factor 35.01\% & weighting factor $23.13 \%$ & weighting factor 57.34\% \\
\hline \multirow{2}{*}{$\mathrm{TiCl}_{3}(3)$} & $g=[1.9658 \pm 0.0174 ;$ & $g=[1.9591 \pm 0.0443 ;$ & $g=[1.9676 \pm 0.0318 ;$ \\
& $1.9704 \pm 0.0734 ;$ & $1.9699 \pm 0.0661 ;$ & $1.9744 \pm 0.0294 ;$ \\
& $1.9890 \pm 0.0183]$ & $1.9853 \pm 0.0353]$ & $1.9963 \pm 0.0092]$ \\
& weighting factor 9.70\% & weighting factor $8.28 \%$ & weighting factor $2.78 \%$ \\
\hline
\end{tabular}


Table S4.

Hyperfine and quadrupole coupling parameters for all nuclei of the active center of $\mathrm{MgCl}_{2}-$ supported Ziegler-Natta catalysts that contribute to HYSCORE spectra (Fig. 3c \& Fig. S11, a).

\begin{tabular}{|c|c|c|c|c|}
\hline Atom & $\mathbf{a}_{\text {iso }}, \mathbf{M H z}$ & $\mathbf{a}$ dip, $\mathbf{M H z}$ & $\mathbf{P}, \mathbf{M H z}$ & $\boldsymbol{\eta}$ \\
\hline$\alpha-\mathrm{H}(1)$ & 1.76 & {$[-1.80-5.337 .14]$} & - & - \\
\hline$\alpha-\mathrm{H}(2)$ & -1.10 & {$[-2.28-6.929 .19]$} & - & - \\
\hline$\beta-\mathrm{H}(1)$ & -8.00 & {$[1.87-0.73-1.14]$} & - & - \\
\hline$\beta-\mathrm{H}(2)$ & -2.62 & {$[4.03-1.81-2.22]$} & - & - \\
\hline$\beta-\mathrm{H}(3)$ & -0.49 & {$[-1.66-2.203 .85]$} & - & 0.699 \\
\hline $\mathrm{Al}$ & 0.31 & {$[-0.36-0.490 .85]$} & -44.71 & - \\
\hline
\end{tabular}




\section{References:}

1. S. Stoll, A. Schweiger, EasySpin, a comprehensive software package for spectral simulation and analysis in EPR. J. Magn. Reson. 178 (1), $42-55$ (2006).

2. I. Gromov, J. Shane, J. Forrer, R. Rakhmatoullin, Y. Rozentzwaig, A. Schweiger, A Q-band pulse EPR/ENDOR spectrometer and the implementation of advanced one- and twodimensional pulse EPR methodology. J. Magn. Reson. 149 (2), 196-203 (2001).

3. Y. Polyhach, E. Bordignon, R. Tschaggelar, S. Gandra, A. Godt, G. Jeschke, High sensitivity and versatility of the DEER experiment on nitroxide radical pairs at Q-band frequencies. Phys. Chem. Chem. Phys. 14, 10762-10773 (2012).

4. F. Neese, The ORCA program system. Wiley Interdisciplinary Reviews: Computational Molecular Science 2, 73-78 (2012).

5. C. Adamo, V. Barone, Toward reliable density functional methods without adjustable parameters: The PBE0 model. J. Chem. Phys. 110 (13), 6158-6170 (1991).

6. S. Grimme, J. Antony, S. Ehrlich, H. Krieg, A consistent and accurate ab initio parametrization of density functional dispersion correction (DFT-D) for the 94 elements H-Pu. J. Chem. Phys. 132, 154104 (2010).

7. A. Klamt, G. Schüürmann, COSMO: a new approach to dielectric screening in solvents with explicit expressions for the screening energy and its gradient. J. Chem. Soc. Perkin Trans 2, 799-805 (1993).

8. F. Neese, F. Wennmohs, A. Hansen, U. Becker, Efficient, approximate and parallel HartreeFock and hybrid DFT calculations. A 'chain-of-spheres' algorithm for the Hartree-Fock exchange. Chem. Phys. 356, 98-109 (2009).

9. F. Weigend, Accurate coulomb-fitting basis sets for $\mathrm{H}$ to Rn. Phys. Chem. Chem. Phys. 8, 1057-1065 (2006).

10. E. Morra, E. Giamello, S. Van Doorslaer, G. Antinucci, M. D'Amore, V. Busico, M. Chiesa, Probing the Coordinative Unsaturation and Local Environment of $\mathrm{Ti}^{3+}$ Sites in an Activated High-Yield Ziegler-Natta Catalyst. Angew. Chem. Int. Ed. 54 (16), 4857-4860 (2015).

11. F. Neese, Software update: the ORCA program system, version 4.0. Wiley Interdisciplinary Reviews: Computational Molecular Science 8 (1), e1327 (2017).

12. F. Neese, Quantum Chemistry and EPR Parameters. eMagRes 6, 1 - 22 (2017).

13. N. Rega, M. Cossi, V. Barone, Development and validation of reliable quantum mechanical approaches for the study of free radicals in solution. J. Chem. Phys. 105 (24), $11060-11067$ (1996).

14. A. Ashuiev et al., https://chemrxiv.org/ndownloader/files/24060725

15. F. Allouche, D. Klose, C. P. Gordon, A. Ashuiev, M. Wörle, V. Kalendra, V. Mougel, C. Copéret, G. Jeschke, Low-Coordinated Ti(III) Alkyl-Molecular and Surface-Complexes: Detailed Structure from Advanced EPR Spectroscopy. Angew. Chem. Int. Ed. 57 (44), 1453314537 (2018). 
16. D. E. Woon, T. H. Dunning, Gaussian basis sets for use in correlated molecular calculations. V. Core-valence basis sets for boron through neon. J. Chem. Phys. 103, 4572 - 4585 (1995).

17. G. Rao, A. B. Altman, A. C. Brown, L. Tao, T. A. Stich, J. Arnold, R. D. Britt, Metal Bonding with 3d and 6d Orbitals: An EPR and ENDOR Spectroscopic Investigation of $\mathrm{Ti}^{3+}-\mathrm{Al}$ and $\mathrm{Th}^{3+}-\mathrm{Al}$ Heterobimetallic Complexes. Inorg. Chem. 58 (12), 7978-7988 (2019).

18. A. Schaefer, H. Horn, R. Ahlrichs, Fully optimized contracted Gaussian basis sets for atoms Li to Kr. J. Chem. Phys. 97, 2571 (1992).

19. M. Cossi, N. Rega, G. Scalmani, V. Barone, Energies, structures, and electronic properties of molecules in solution with the C-PCM solvation model. J. Comput. Chem. 24, $669-681$ (2003).

20. E. D. Glendening, C. R. Landis, F. Weinhold, Natural bond orbital methods. WIREs Comput. Mol. Sci. 2, 1-42 (2012).

21. A. J. Pell, G. Pintacuda, C. P. Grey, Paramagnetic NMR in solution and the solid state. Prog. Nucl. Mag. Res. Sp. 111, 1-271 (2019).

22. W. B. Mims, Envelope Modulation in Spin-Echo Experiments. Phys. Rev. B 5 (7), 2409-2419 (1972).

23. G. Feher, Observation of Nuclear Magnetic Resonances via the Electron Spin Resonance Line. Phys. Rev. 103, 834 (1956).

24. E. Grau, A. Lesage, S. Norsic, C. Copéret, V. Monteil, P. Sautet, Tetrahydrofuran in $\mathrm{TiCl}_{4} / \mathrm{THF} / \mathrm{MgCl}_{2}$ : a Non-Innocent Ligand for Supported Ziegler-Natta Polymerization Catalysts. ACS Catal. 3 (1), 52-56 (2013).

25. G. Natta, P. Pino, G. Mazzanti, U. Gianini, A crystallizable organometallic complex containing titanium and aluminium. J. Am. Chem. Soc. 79 (11), 2975-2976 (1957).

26. A. Skorobogaty, R. Lancashire, T. D. Smith, J. R. Pilbrow, G. R. Sinclaire, Optical and Electron Spin Resonance Studies of Copper(II), Nickel(II) and Oxovanadium(IV) Complexes of Water-soluble Phthalocyanine and Porphyrazine Chelates Absorbed on Sephadex Resins, and the Effect of Added Dithionite. J. Chem. Soc., Faraday Trans. 2 79, 1123-1141 (1983).

27. J.P. Perdew, Density-functional approximation for the correlation energy of the inhomogeneous electron gas. Phys. Rev. B 33, 8822 - 8824 (1986).

28. F. Weigend, R. Ahlrichs, Balanced basis sets of split valence, triple zeta valence and quadruple zeta valence quality for $\mathrm{H}$ to Rn: Design and assessment of accuracy. Phys. Chem. Chem. Phys. 18, $3297-3305$ (2005).

29. F. Neese, Approximate second-order SCF convergence for spin unrestricted wavefunctions. Chem. Phys. Lett. 325, 93 - 98 (2000).

30. J. P. Perdew, J. Tao, Meta-generalized gradient approximation: Explanation of a realistic nonempirical density functional. J. Chem. Phys. 120 (15), 6898 - 6911 (2004).

31. C. P. Gordon, S. Shirase, K. Yamamoto, R. A. Andersen, O. Eisenstein, C. Copéret, . NMR chemical shift analysis decodes olefin oligo- and polymerization activity of d0 group 4 metal complexes. Proc. Natl. Acad. Sci. 115 (26), 5867-5876 (2018). 
32. M. Humbert, S. Norsic, J. Raynaud, V. Monteil, Activity enhancement of $\mathrm{MgCl}_{2}$-supported Ziegler-Natta catalysts by Lewis-Acid pre-treatment for ethylene polymerization. Chinese $J$. Polym. Sci. 37, 1031-1038 (2019). 
